\title{
Reseña de Sentencias del Tribunal Supremo (Primer trimestre de 1993)
}

\author{
María del Rosario Alonso Ibáñez
}

Prof. Titular de Derecho Administrativo

Universidad de Oviedo

Sumario: I. FUENTES. II. ORGANIZACION ADMINISTRATIVA. III. HACIENDAS LOCALES. IV. EMPLEO PUBLICO. V. SANCIONES. VI. RESPONSABILIDAD PATRIMONIAL. VII. BIENES PUBLICOS. VIII. URBANISMO.

\section{FUENTES}

1. Decreto del Gobierno Vasco sobre admisión de alumnos a los Centros públicos y concertados. Exigencia preceptiva del Dictamen del Consejo de Estado en la elaboración de reglamentos autonómicos dictados en desarrollo de leyes básicas estatales. Intervención en el procedimiento de elaboración del reglamento de órganos consultivos de la Administración Autonómica. Competencias de las Comunidades Autónomas en el desarrollo de la Ley Orgánica del Derecho a la Educación.

\section{FUNDAMENTOS DE DERECHO}

PRIMERO. El Gobierno Vasco promueve recurso de revisión contra la Sentencia de la Sala Tercera, Sección Tercera, de este Tribunal Supremo de 7-3-1991, dictada en apelación, que confirmó la de primera instancia pronunciada por la Sala de la Jurisdicción de la antigua Audiencia Territorial de Bilbao en 13-6-1988. La cuestión decidida, en sentido idéntico, por ambas sentencias fue la invalidez del Decreto 74/1986, de 18 de marzo del Consejo de Gobierno de dicha Comunidad Autónoma regulando la admisión de alumnos en los Centros Públicos y Concertados sitos en el territorio de aquélla, por no haberse emitido, en el procedimiento de elaboración, dictamen de la Comisión Permanente del Consejo de Estado, trámite que se consideró preceptivo conforme al art. 23, segundo párrafo, en relación con el art. 22.3 ambos de la Ley Orgánica 3/1980, de 22 de abril, Reguladora del Alto Cuerpo 
Consultivo. La rescisión de la sentencia firme del Tribunal Supremo se pretende al amparo del art. 102.1.b), en su redacción anterior a la Ley 10/1992 por estimar el Gobierno Vasco demandante que tal sentencia es contradictoria, en primer término, con la S. 1-6-1990, de este Tribunal Supremo, y con carácter subsidiario, con la emanada de la antigua Sala Cuarta de este mismo Tribunal de 17-2-1988. El referido planteamiento obedece, según arguye la parte actora, a que el primer plano de contradicción descansa en la antagónica posición de criterios jurisdiccionales en orden a la preceptiva consulta al Consejo de Estado, por las Comunidades Autónomas, de Reglamentos Autonómicos dictados como desarrollo legislativo de Leyes Estatales conteniendo normas básicas sobre una determinada materia, sosteniendo el Ente Público demandante que la tesis negativa, mantenida en la antecedente $\mathrm{S}$. 1-6-1990, ha de prevalecer, y ello haría innecesario acudir al segundo extremo o cuestión objeto de recurso, es decir, supuesta la preceptividad de dicha consulta, la misma sería innecesaria en el caso, dada la intervención en el procedimiento de elaboración del Decreto del Gobierno Vasco de órganos consultivos de la Administración Autonómica, tesis que se afirma sostenida por la Sentencia antecedente de 17-21988, al menos con carácter implícito. Así, pues, procederemos por separado a examinar la alegada contradicción en cada uno de los referidos aspectos y por el orden lógico y de exposición del escrito de demanda.

SEGUNDO. La contradicción con la S. 1-6-1990 se produce, en contra de lo alegado, en su impugnación al recurso, por la Abogacía del Estado. En efecto, la identidad sustancial que exige el art. 102.1.b.) de la Ley de esta Jurisdicción, para abrir la vía casacional en que se condensa la función que cumple esta modalidad de recurso, viene referida, además de al aspecto subjetivo o de los litigantes, que no se pone aquí en tela de juicio, a los hechos, fundamentos y pretensiones, respecto de los que se predica que sean "sustancialmente iguales"; pues bien, si los hechos han de ser iguales en lo sustancial, es decir, al núcleo de lo debatido en el litigio, poco importa que la materia sobre que versó el Reglamento autonómico en uno y otro caso no fuera la misma, pues lo decisivo no es tal materia objeto de regulación por la norma reglamentaria autonómica, sino si se trata de un instrumento normativo del mismo carácter y ejercitado en la misma posición, en relación con la Ley Estatal, en uno y otro caso, al efecto de exigir como preceptivo el dictamen a que venimos refiriéndonos. Y esta identidad se produce aquí en términos inequívocos, dado que la S. 1-6-1990 se enfrentó a un Reglamento autonómico, el Decreto 43/1986, de 15 de mayo, aprobado por el Consejo de Gobierno de la Comunidad Autónoma de las Islas Baleares, sobre Cajas de Aho- 
JURISPRUDENCIA

rro, Organos Rectores y Control de Gestión, que implica desarrollo legislativo "en el marco de la legislación básica del Estado», del art. 11.4 de su Estatuto de Autonomía (Ley Orgánica 2/1983, de 25 de febrero), e incluso de la Ley Estatal conteniendo normas básicas sobre la materia, tal y como la Ley 31/1985, de 2 de agosto de Normas Básicas sobre Organos Rectores de Cajas de Ahorro. Es decir, se trataba allí de una norma reglamentaria autonómica dictada en desarrollo de Ley Básica Estatal, al igual que sucede en el caso de la sentencia impugnada, en que el Gobierno Vasco, por medio del Decreto 74/1986, de 18 de marzo, desarrolla - siquiera sea parcialmente- una norma básica estatal, como es la Ley Orgánica 8/1985, de 3 de julio, Reguladora del Derecho a la Educación (abreviadamente, por sus siglas de LODE), en derivación de la competencia - que no es ni se califica estatutariamente de plena no exclusiva - que le viene atribuida por su Estatuto de Autonomía en el art. 16, norma peculiar que trae causa de la disposición adicional $1^{a}$ de la Constitución, en materia de enseñanza o educación, competencia que según dicha norma estatutaria se ejercerá "sin perjuicio del art. 27 de la Constitución y Leyes Orgánicas que lo desarrollen, de las facultades que atribuye al Estado el art. $149.1 .30^{\mathrm{a}}$ de la misma y de la alta inspección necesaria para su cumplimiento y garantía». Pues bien, a pesar de la sustancial identidad de los instrumentos normativos regionales, en la sentencia antecedente se entendió que el dictamen de la Comisión Permanente del Consejo de Estado no venía exigido de modo preceptivo, a diferencia del criterio opuesto, favorable a la necesaria consulta, sustentado por la sentencia impugnada. Se hace preciso, pues, dilucidar cuál de las dos tesis enfrentadas se acomoda al Ordenamiento jurídico, a los efectos unificadores que presiden esta modalidad de recurso.

TERCERO. Antes de abordar este primer problema de fondo, y para hacerlo con las mayores garantías de acierto, se hace preciso sentar una premisa, que aun extramuros, formalmente, del debate procesal, viene a poner claridad en tema tan arduo y no pacífico en la doctrina ni en la jurisprudencia. La misma atañe a la constitucionalidad del párrafo segundo del art. 23 de la Ley Orgánica 3/1980, del Consejo de Estado, en los términos en que la ha declarado la S. 204/1992, de 26 de noviembre, del Pleno del Tribunal Constitucional (Boletín Oficial del Estado del día 23-12-1992), decidiendo cuestión de inconstitucionalidad que en relación con el citado precepto había suscitado la Sala de lo Contencioso-Administrativo del Tribunal Superior de Justicia de la Comunidad Valenciana, en recursos acumulados promovidos por diversos empresarios de juegos contra el decreto 89/1990, de 11 junio, del Consell de la Generalidad Valenciana, por el que se aprobó el Reglamento del Juego del Bingo. 
Pues bien, el fundamento jurídico sexto y último de dicha sentencia y de su fallo, en conexión con el resto de la fundamentación jurídica, se concluye que en la elaboración de Reglamentos autonómicos que se dicten en ejecución de las leyes (supuesto que se inscribe en la materia de las bases del régimen jurídico de las Administraciones Públicas y del procedimiento administrativo común, según la jurisdicción constitucional), el art. 23, párrafo segundo, en relación con el art. 22.3 de la ya citada Ley Orgánica del Consejo de Estado, en cuanto exigen dictamen previo y preceptivo recabado de la Comisión Permanente del Consejo de Estado, no es contrario a la Constitución «siempre que se entienda que el dictamen del Consejo de Estado se exige a las Comunidades autónomas sin organismo consultivo propio". Dicho de otra forma, la preceptividad del dictamen del Alto Cuerpo Consultivo, en el caso de los Reglamentos autonómicos antes referidos, sólo puede ser eludida, válidamente, cuando en el procedimiento de elaboración de dichas normas haya mediado la consulta de Organos homologables al Consejo de Estado, dotados de características orgánicas y funcionales semejantes a éste, insertos en el seno de la Administración Autonómica correspondiente. Importa destacar que dicha sentencia del Tribunal Constitucional asigna la función consultiva atribuida al Consejo de Estado un ámbito no constreñido a los literales términos del art. 107 de la Constitución, sino más amplio, como órgano consultivo con relevancia constitucional "al servicio de la concepción del Estado que la propia Constitución establece", reiterando términos de su anterior S. 56/1990, tal como luce en el fundamento jurídico segundo de la S. 204/1992 a que venimos aludiendo, lo que lleva a concluir que la intervención del Consejo de Estado en relación con determinadas actuaciones administrativas de las Comunidades Autónomas no es atentatoria a la potestad de autoorganización que a éstas les confiere el art. 148.1.1 ${ }^{\text {a }}$ de la Norma Fundamental.

CUARTO. Asiste razón al Gobierno Vasco al sostener que, desde un punto de un punto de vista de rigurosa técnica, no son homologables los Reglamentos ejecutivos de las Leyes (sean éstas estatales o autonómicas) y aquellos otros reglamentos que las Comunidades Autónomas aprueban, en el marco de la legislación básica estatal y partiendo de los límites que esta normación básica impone al desarrollo legislativo regional, en materias de competencia concurrente o compartida entre el Estado y los Entes Autonómicos, como es el caso tanto del Decreto 43/1986 de las Islas Baleares, sobre Cajas de Ahorro, como del ahora cuestionado, Decreto 74/1986 del Gobierno Vasco sobre admisión de alumnos a los Centros Públicos y Concertados, producidos ambos como operaciones de desarrollo normativo dentro del marco de las Leyes Básicas Estatales, como las Leyes antes referidas, concretada en el caso que nos ocupa, por la Ley 
Orgánica del Derecho a la Educación, Ley Orgánica 8/1985. Ha de afirmarse que, en efecto, no se trata tanto, en estos supuestos, de completar, pormenorizar, detallar o precisar una anterior regulación a nivel de Ley (que es lo propio de los Reglamentos ejecutivos a que se refiere el art. 22.3 de la Ley Orgánica del Consejo de Estado), sino de ejercitar una competencia autonómica, en el plano normativo reglamentario, con sujeción o atenida a los límites que la uniformidad de la legislación básica estatal le impone, lo que permite a la Comunidad Autónoma introducir en la regulación opciones políticas propias, acomodadas a sus peculiares características, siempre que no desvirtúen las normas básicas estatales, por lo que, así considerados estos instrumentos normativos, más que desarrollar las normas básicas la función que cumplen es complementar el Ordenamiento jurídico a cuya formación concurren los dos tipos de Entes Públicos territoriales con poder normativo. Ahora bien, aun siendo ello así, la cuestión no queda solventada sin más en favor de la tesis mantenida por el Gobierno Vasco, pues se hace preciso determinar, en una exégesis finalista y no literal de los preceptos en juego, si a pesar de la peculiar posición de estos Reglamentos autonómicos, o de su especificidad, ha de mediar en su elaboración el dictamen preceptivo de la Comisión Permanente del Consejo de Estado, en tanto - según la interpretación del Tribunal Constitucional- no cuentan con Órganos Consultivos propios. Ni desde una perspectiva institucional, ni de la más concreta de la finalidad de tal dictamen, debe éste ser eludido en el procedimiento administrativo común de elaboración de reglamentos, según pasamos a analizar en el siguiente fundamento.

QUINTO. Desde la perspectiva de la autoorganización que se reserva a las Comunidades Autónomas ex art. 148.1, $1^{\text {a }}$ de la Constitución, no es inmisión ilegítima la exigencia del trámite de consulta por parte de un Organo que no pertenece en rigor a la Administración Central ni en ella se encuadra, dada su posición en el Ordenamiento y la «auctoritas" que le confiere su configuración organizativa y funcional, como es el Consejo de Estado, por lo que la intervención consultiva de éste, sin carácter vinculante por otra parte, en nada empece ni a dicho principio de autoorganización ni a la autonomía en la gestión de los intereses propios que a las Comunidades Autónomas reconoce y garantiza el art. 137 del Texto Constitucional.

En otro orden de cosas y atendiendo a la finalidad que cumple el controvertido dictamen, entendido éste más que como un control de legalidad pura y simple, como un requisito garantizador en el procedimiento de elaboración de Reglamentos, es lo cierto que, aun respetando las opciones políticas propias a que antes aludíamos, las normas reglamentarias autonómicas incorporan, sin duda, un cierto grado de 
aplicación o concreción a su ámbito territorial de la legislación básica estatal sobre la materia, y trasladan o deben trasladar a éste las determinaciones básicas que vienen obligados a respetar. Por lo que al caso atañe, el Gobierno Vasco, al aprobar el Decreto sobre admisión de alumnos a los Centros Educativos Públicos y Concertados existentes en su ámbito, los criterios o prioridades que fijan los arts. 20.2 y 53 de la Ley Orgánica 8/1985 (LODE), y en tal sentido, podrá sostenerse razonablemente que el dictamen del Alto Cuerpo Consultivo no está llamado a valorar los aspectos de oportunidad y conveniencia de la regulación autonómica, por no exigirlo ni hacerlo aconsejable la índole de la materia (en adecuación a lo señalado en el art. $2^{\circ} .1$ de su Ley Orgánica Reguladora), pero será difícil negar que la adecuación a la Constitución y a la Ley Básica Estatal, por parte del Reglamento autonómico, como finalidad garantizadora de dicho examen previo, se halla en el mismo plano de preservar el imperio de la Ley que cuando el dictamen se produce en la relación entre Ley y Reglamento ejecutivo o de desarrollo de la misma, ya que no debe olvidarse que al Consejo de Estado incumbe velar por la observancia de la Constitución y del resto del Ordenamiento jurídico conforme a lo que previene el art. $2^{\circ} .1$, antes citado, de su Ley Orgánica. A este respecto no es desdeñable el dato de que nos hallamos ante materia, como la de educación o enseñanza, en que la competencia del Gobierno Vasco, bien que con raíces en la Disposición adicional primera de la Constitución, enmarca en el art. 27 de ésta y de las Leyes Orgánicas que desarrollen este capital precepto, así como de las facultades que al Estado atribuye el art. 149.1.30 de la Norma Suprema, según el propio art. 16 del Estatuto de Autonomía para el País Vasco (Ley Orgánica 3/1979, de 18 de diciembre) deja claramente establecido. Si la enunciación de supuestos requeridos de consulta preceptiva, contenida en el art. 22 de la Ley Orgánica del Consejo de Estado, se realiza quizás desde la perspectiva de la Administración General del Estado, ello no impide, sino antes al contrario, determina que cuando la potestad reglamentaria sea ejercitada por los Gobiernos de las Comunidades Autónomas, aun en aplicación de normas básicas del Estado, el dictamen de la Comisión Permanente del Alto Cuerpo Consultivo se establezca también como preceptivo, comprendiendo la hipótesis en el ap. 3 del citado art. 22, pues la actuación consultiva se dirige a la preservación del "común denominador normativo" en que las normas básicas consisten, en la expresiva terminología de la STC 1/1982, de 28 de enero.

En conclusión, la tesis que ha de prevalecer, como jurídicamente correcta es la de la sentencia impugnada, del carácter preceptivo de la referida consulta, dado que, como después se verá, la Comunidad Autónoma del País Vasco, no tenía en el momento de la elaboración del De- 
JURISPRUDENCIA

creto cuestionado, un Órgano consultivo de características similares al Consejo de Estado.

SEXTO. La contradicción con la S. 17-2-1988 aparece como menos nítida, pues ésta sostiene el carácter sustituible del dictamen del Órgano Consultivo Estatal por el de las Comunidades Autónomas cuando inserten en su Administración Consultiva un órgano de características semejantes a aquél, cuestión que no aborda directamente la sentencia impugnada, si bien no excepciona este supuesto. Aun entendiendo como más plausible, jurídicamente, la tesis de la sentencia antecedente, que ha venido a ser aceptada por el Tribunal Constitucional en la citada S. 204/1992, lo cierto es que los casos no son homologables, a efectos de la pretendida rescisión de la sentencia impugnada, que declaró nulo, por vicio de omisión del dictamen previo del Consejo de Estado, el Decreto cuestionado. Pues a diferencia de la S. 17-2-1988, referida al Decreto 169/1983, de 12 de mayo, sobre unidades mínimas de cultivo, de la Generalidad de Cataluña, en que en el procedimiento de su elaboración fueron oídos los órganos consultivos autonómicos, en la sentencia recurrida este requisito no pudo cumplirse, al carecer la Comunidad Autónoma del País Vasco de Organo consultivo homologable con el Consejo de Estado, requisito exigido por la citada sentencia del Tribunal Constitucional. En efecto, a diferencia de las Administraciones Autonómicas de Cataluña y Canarias que, con el mencionados carácter de independencia orgánica y funcional, han constituido, mediante sendas Leyes autonómicas, Órganos consultivos propios, la Comunidad del País Vasco no disponía de tal tipo de órgano de asesoramiento, sin que a estos efectos pueda atribuirse el carácter de tal a la Viceconsejería de Justicia y Desarrollo Legislativo, perteneciendo a la Administración activa, aun cuando un Decreto Autonómico le atribuyese el carácter de Centro Superior Consultivo de la Administración Común del País Vasco, según alega el Gobierno Vasco demandante. No se ha acreditado que dicho órgano administrativo se hallase dotado "de las características de organización y funcionamiento que aseguren su independencia, objetividad y rigurosa cualificación técnica» dicho en términos de apreciación general y objetiva y con palabras de la S. 204/1992 de reiterada cita, y en consecuencia, la nota de sustituibilidad o fungibilidad de ambos dictámenes no es aquí constatable.

SEPTIMO. En resumen de cuanto antecede, la tesis de la sentencia impugnada ha de ratificarse, como ajustada a Derecho, al declarar la nulidad del Decreto 74/1986, de 18 marzo, aprobado por el Consejo de Gobierno de la Comunidad Autónoma del País Vasco, sobre admisión de alumnos en Centros Públicos y Concertados, por omisión del dictamen preceptivo de la Comisión permanente del Consejo de Estado, nu- 
lidad que es la consecuencia jurídica apropiada al apreciarse la concurrencia del motivo invalidante en recurso directo frente al Reglamento autonómico, como es el caso que nos ocupa, y frente a cuya acertada tesis no deben prevalecer las divergencias contenidas en las sentencias invocadas como "antecedentes" por el Gobierno Vasco demandante. Se impone, por tanto, la improcedencia del recurso de revisión por éste promovido, sin dar lugar a la rescisión de la sentencia firme impugnada.

\section{FUNDAMENTOS DE DERECHO (Voto particular)}

PRIMERO. Para la resolución de este recurso de revisión formulado al amparo del art. 102.1.b) de la Ley Reguladora de esta Jurisdicción en su anterior redacción a la Ley de Medidas Urgentes de Reforma procesal de 30-4-1992, debe dilucidarse, en primer término, si la contradicción aducida por la representación del Gobierno de la Comunidad Autónoma del País Vasco concurre entre la Sentencia recurrida dictada por la Sala Tercera, Sección $3^{a}$ de este Tribunal Supremo, de 7-3-1991 Recurso de Apelación 2258/1988, y las de 1-6-1990 de la misma Sala Sección Quinta y 17-2-1988 Sala Cuarta, al incidir: identidad de situación de los litigantes e igualdad sustancial en los hechos, fundamentos, y pretensiones, para, en el supuesto de admitir que se da esa premisa exigida por dicho precepto y consecuentes pronunciamientos distintos, declarar la doctrina prevalente en función de la legalidad aplicable, y, en su caso, rescindir la sentencia impugnada en base al mentado motivo de revisión casacional, de ser procedente la alegada por el demandante, y rechazar el recurso interpuesto por el Abogado del Estado contra el Decreto del Gobierno Autónomo Vasco del Departamento de Educación, Universidades e Investigación del Gobierno Vasco de 18-31986 declarado nulo de pleno derecho por la Sentencia de la Sala de lo Contencioso-Administrativo de la Audiencia Territorial de Bilbao de 13-6-1988, por no haber informado la Comisión Permanente del Consejo de Estado esa disposición según lo dispuesto en el art. 22.3 en relación con el párrafo segundo del art. 23, confirmada por la recurrida en este proceso de revisión.

SEGUNDO. La identidad sustancial entre las partes litigantes en los recursos en los que se dictaron las sentencias que por el Gobierno Vasco en este proceso se estiman contradictorias es evidente pues en las tres sentencias se resolvieron recursos de apelación en los que las partes procesales intervinientes fueron los Gobiernos Autónomos de la Generalidad de Cataluña y de las Islas Baleares y el Gobierno Vasco y, por 
otra, la Administración del Estado; postulando aquéllos la legalidad de unas disposiciones adoptadas por sus Consejos de Gobierno en forma de Decretos por no ser exigible el dictamen preceptivo de la Comisión Permanente del Consejo de Estado, y por el Abogado del Estado ser preceptivo este trámite en la elaboración de una disposición general dictada en ejecución de una Ley del Estado por el Gobierno de una Comunidad Autónoma; sustancial identidad que concurre, en consecuencia, también en las pretensiones y fundamentos esgrimidos, relativos a la aplicabilidad o no de las normas de la Ley Orgánica del Consejo de Estado de 22-4-1980 a que se ha hecho mención en el apartado anterior; y asimismo en las pretensiones ejercidas por las Administraciones de las Comunidades Autónomas recurrentes en apelación frente a las de nulidad por el Abogado del Estado en primera instancia respecto a unos Decretos cuyo contenido en relación con el objeto de su regulación y competencia de la Comunidad Autónoma, puede ser determinante de la exigibilidad o no del dictamen del Consejo de Estado, de lo que se infiere que la cuestión debatida comporta el estudio de las sentencias aducidas como contradictorias para concluir si los Decretos impugnados son considerados sustancialmente idénticos en dichas sentencias para estimar o no la que sostiene el recurrente y niega el Abogado del Estado.

TERCERO. El demandante opone como contradictoria a la recurrida la de 1-6-1990 y, subsidiariamente la de 13-2-1988, alegando respecto a la primera que dada la igualdad sustancial de los elementos subjetivos y objetivos contemplados en ambas sentencias no eran aplicables el art. 23-2) en relación con el 22-3) de la Ley Orgánica del Consejo de Estado, y, por ende, no era exigible el dictamen del Consejo de Estado, y en cuanto a la segunda de las sentencias invocadas como contradictorias, por concurrir los mismos elementos de carácter subjetivo y objetivo, y presuponiendo aplicables dichos preceptos no lo serían al caso a que se contrae la sentencia recurrida: según la interpretación dada a los mismos en la sentencia opuesta que debería dar lugar a una conclusión contraria a la de la sentencia objeto del recurso.

CUARTO. El Decreto anulado por la Sala de lo Contencioso-Administrativo de la Audiencia Territorial de Bilbao relativo a la regulación de la admisión de alumnos en los Centros Públicos Concertados de la Comunidad Autónoma del País Vasco en Sentencia confirmada por la recurrida en este proceso de revisión de 7-3-1991 no guarda similitud alguna con los Decretos de los Gobiernos de las Comunidades Autónomas de Baleares y Cataluña de 15-5-1986 sobre Cajas de Ahorro y Control de Gestión y de 12-4-1983 sobre Unidades Mínimas de Cultivo respectivamente, objeto de las SS. 1-6-1990 y 17-2-1988, en cuanto las 
materias comprendidas en su normativa reglamentaria, lo que no excluiría una posible similitud en cuanto al proceso de elaboración de esas normas reglamentarias con la contemplada en la sentencia impugnada en revisión, toda vez que podría incidir una igualdad sustancial en orden a la clase de competencia de los respectivos Gobiernos de las Comunidades Autónomas según los preceptos de la Constitución y de los respectivos Estatutos de Autonomía y la cobertura legal de esas disposiciones, y su naturaleza como reglamentos de ejecución de una Ley de los órganos legislativos del Estado, o de la Comunidad Autónoma, o la concurrencia de competencias; siendo imperativo a estos efectos, partir de la doctrina contemplada en cada una de las sentencias dictadas en apelación para discernir si dado el supuesto fáctico concurrente en cada una de ellas se da la contradicción esgrimida por el recurrente sobre la exigibilidad del dictamen del Consejo de Estado.

QUINTO. La sentencia impugnada en este recurso en sus Fundamentos de Derecho del fallo desestimatorio del recurso de apelación contra la S. 13-6-1988 del Tribunal de instancia que declaró nula la disposición reglamentaria contenida en el Decreto de 18-3-1986, estima que esta disposición promulgada para regular la admisión en los Centros Públicos y Concertados de la Comunidad Autónoma del País Vasco, materia incardinada dentro del principio constitucional garantizador del derecho a la educación en íntima relación con el de libertad de enseñanza a que aluden el ap.1.a) y b) del art. 27 de la Constitución y en conexión con el derecho de los padres y tutores a la libre elección del centro escolar, es un reglamento ejecutivo dictado de conformidad con lo dispuesto en la Disposición Final Primera de la Ley Orgánica Reguladora del derecho a la educación de 3-7-1985: «El Gobierno y las Comunidades Autónomas, en el ámbito de sus respectivas competencias, podrán dictar cuantas disposiciones sean precisas para la aplicación de la presente Ley" y en concreto dicho Decreto contempla la ejecución de los arts. 20 y 53 de ese Cuerpo Legal, no teniendo la consideración de reglamento independiente emanado de la competencia establecida en el Estatuto de Autonomía del País Vasco de 18-121979, art. 16, sino en virtud de los dispuesto en la mentada Disposición Final Primera de la citada Ley promulgada en cumplimiento de la competencia exclusiva del Estado art. 149-1-30 de la Constitución: "regulación de las condiciones de obtención, expedición, y homologación de títulos académicos y profesionales, y normas básicas para el desarrollo del art. 27 de la Constitución a fin de garantizar las obligaciones de los poderes públicos en esta materia»; teniendo por finalidad, según su exposición de motivos, la Ley Orgánica del Derecho a la Educación aprobar las normas básicas para el desarrollo del art. 27 de la Constitución, que corresponde a una competencia exclusiva del Estado; sin que de 
los preceptos del Decreto del Gobierno Vasco de 18-3-1986, ni de las alegaciones de la recurrente en este proceso, se deduzca que al hacer uso de su competencia el Gobierno Vasco para dictar el Decreto en ejecución de la Ley del Derecho a la Educación, emanada de los órganos legislativos del Estado, se complementaran las disposiciones que traen causa de dicha Ley con otras de la Comunidad Autónoma y, por ende, ajenas a las del Estado; de lo que se infiere que el supuesto de hecho es distinto del contemplado en la S. 1-6-1990 aunque se entendiera que en el caso de existir una Ley de la Comunidad Autónoma que regulara la materia a que hace referencia el Decreto del Gobierno Vasco éste tuviera opción de integrarla en el Reglamento de desarrollo y ejecución de la Ley Estatal pues esta integración de existir una Ley de la Comunidad no se produjo ni ha sido alegada, en esa norma; que no guarda relación alguna con la regulación de las Cajas de Ahorro, Órganos Rectores, y Control de Gestión a que se refiere esa sentencia que entendió que no eran aplicables los art. 23-2) y 22-3) de la Ley Orgánica del Consejo de Estado al Decreto del Gobierno de la Comunidad Autónoma de Baleares que reguló esta materia; como tampoco puede estimarse que incide igualdad sustancial entre la materia regulada por el Decreto del Gobierno Vasco y el de la Generalidad de Cataluña que reguló las unidades mínimas de cultivo por Decreto de 12-4-1983, ya que sobre esta materia el Estatuto de Autonomía confiere a esa Comunidad Autónoma competencia exclusiva del art. 12-1-4 del Estatuto de Autonomía de Cataluña: Agricultura y Ganadería, de acuerdo con las bases y la ordenación de la actividad económica general y la política monetaria del Estado y en los términos de lo dispuesto en los arts. 38 y 131, y en los núms. 11 y 13 del apartado primero del art. 149 de la Constitución según prescribe este artículo del Estatuto de Autonomía Catalán; de lo que se infiere que este Decreto del Gobierno de la Generalidad, para el que la S. 17-2-1988 de la antigua Sala Cuarta de este Tribunal entendió que no era preceptivo el dictamen del Consejo de Estado, no es identificable por su objeto con el Decreto del Gobierno Vasco, a que se refiere este proceso, dictado en ejecución de una Ley Estatal y no en el ejercicio de una competencia legislativa de la Comunidad Autónoma.

SEXTO. De lo expuesto en los apartados anteriores se deduce inequívocamente que no incide la contradicción aducida por el demandante entre la sentencia recurrida y las opuestas para tener que formular un juicio sobre cuál de las doctrinas es la prevalente y conforme con la legalidad aplicable, en el sentido de afirmar, como pretende el recurrente, que el art. 23-2) en relación con el 22-3) de la Ley Orgánica del Consejo de Estado no es aplicable al caso controvertido y resuelto por la Sentencia impugnada, o subsidiariamente de conformidad con la doctrina a que se refiere la S. 17-2-1988 la materia del Decreto recurri- 
do y en función de la interpretación que debe hacerse de dichos preceptos, no era exigible en este caso el dictamen previo del Consejo de Estado; por todo lo cual debe rechazarse el recurso interpuesto e imponer las costas al recurrente de conformidad con lo dispuesto en el art. 1809 de la Ley de Enjuiciamiento Civil al que se remitía el art. 102-2) de la Ley de la Jurisdicción Contencioso-Administrativa en su anterior redacción.

(Sentencia de 16 de enero 1993. Ar. 342. Recurso extraordinario de revisión. Ponente: P. García Manzano).

2. Autonomía financiera de las Comunidades Autónomas. Fondo de Compensación Interterritorial. Decisiones del Gobierno en materia de política presupuestaria de carácter coyuntural que afectan a las decisiones del Fondo de Compensación. Acuerdos del Consejo de Ministros que disminuyen los ingresos de una Comunidad Autónoma y afectan a los gastos proyectados para un ejercicio económico.

\section{FUNDAMENTOS DE DERECHO}

CUARTO. Alega en primer lugar la Comunidad recurrente que el art. 57.1.b.) de la Ley Presupuestaria —que autoriza al Gobierno, en función de la política presupuestaria de coyuntura económico-social, a no disponer de hasta un 10\% como máximo de los créditos para operaciones de capital que figuren en los Presupuestos del Estado y Organismos Autónomos del respectivo ejercicio-, no es aplicable al Fondo de Compensación Interterritorial, puesto que su distribución corresponde únicamente a las Cortes Generales del Estado, según el art. 158.2 de la Constitución, a favor de las cuales existiría una absoluta reserva. Esta Sala ya ha resuelto un recurso análogo al actual por S. 6-11-1992, cuya doctrina debe de ser reiterada ahora. Según la mencionada sentencia, el art. 158 de la Constitución, en su ap. 2 estableció la obligación de constituir un Fondo de Compensación con destino a gastos de inversión de las Comunidades Autónomas y de las Provincias, en su caso, cuyos recursos serían distribuidos entre ellas por las Cortes Generales; por su parte, el art. 157.1.c.) incluyó las transferencias de dicho Fondo entre los recursos de las Comunidades Autónomas, estableciendo en su art. 74.2 el procedimiento para la adopción del referido acuerdo de distribución. Aunque en el art. 140 del Reglamento del Senado de 26-51982 se desarrolle el citado procedimiento, por la Ley de 31-3-1984 se realizó una completa regulación del mismo, determinando su cuantía total y las distintas variables en atención a las cuales ha de distribuirse 
entre los territorios beneficiados, imponiendo al Gobierno la obligación de consignar en los Presupuestos Generales del Estado de cada ejercicio no sólo la dotación general del fondo, sino la que corresponde a cada Comunidad con relación expresa de los proyectos de inversión a que haya de destinarse. Desde la perspectiva de la reserva absoluta en favor de las Cortes Generales, en favor del Acuerdo de Distribución del Fondo de Compensación, el mecanismo indicado no se compadece con la tesis de la Comunidad recurrente, puesto que implica la atribución al gobierno, conforme al art. 134.1 de la Constitución, de la facultad, lógicamente condicionada en cuanto a su validez al cumplimiento de los límites impuestos por la Ley de 31-3-1984, de incluir en los Presupuestos Generales del Estado no sólo la partida correspondiente a la dotación del Fondo de Compensación, sino de las distintas partidas relativas a su particular distribución territorial.

QUINTO: Argumenta la Comunidad recurrente que el contenido de las dotaciones del Fondo de Compensación no puede quedar sujeto a las decisiones del Gobierno en materia de política presupuestaria y mucho menos a las que tengan carácter coyuntural, como es el caso de las que se adoptan en virtud de las facultades concedidas en el art. 57.1.b) de la Ley Presupuestaria, porque afecta al ejercicio de las competencias asumidas por las Comunidades Autónomas, en cuanto el destino del mismo es la financiación de proyectos de inversiones que no pueden sufragarse por la participación en los ingresos tributarios del Estado.

Este argumento obliga a delimitar, por un lado las relaciones entre la política presupuestaria del Gobierno plasmada en los Presupuestos Generales del Estado y el Fondo de Compensación Interterritorial, y, de otro lado, la incidencia que en éste pueden tener las decisiones presupuestarias de naturaleza coyuntural adoptadas conforme a las previsiones del art. 57.1.b) de la Ley General Presupuestaria.

Respecto de lo primero, hay que partir de que los Presupuestos Generales del Estado en cuanto expresión contable del conjunto de ingresos que se prevea obtener en el ejercicio correspondiente por el Estado, Organismos Autónomos y restantes Entes del Sector Público estatal y de los gastos que como máximo puedan realizarse en el mismo período, siendo también y marcadamente el principal instrumento de la política económica del Gobierno. Dentro de los Presupuestos Generales, la consignación para el Fondo de Compensación no se contempla como un partida autónoma independiente de las demás, sino íntimamente relacionada con las otras tan ligadas a las decisiones sobre política económica a que responde el Presupuesto, como sin las relativas a la inversión pública. A este respecto, el art. 16.1.2. de la Ley Orgánica de 22- 
9-1980, de Financiación de las Comunidades Autónomas dice que, el Fondo de Compensación se dotará anualmente en cantidad no inferior al 30\% de la inversión pública que haya sido aprobada en los Presupuestos Generales del Estado. Por su parte, el art. 3 de la Ley de 31-31984 Reguladora del Fondo de Compensación establece que, a estos efectos, se entenderá por inversión pública el conjunto de gastos destinados a inversiones reales que figuren en los Presupuestos Generales del Estado, incluidas las del propio Fondo de Compensación Interterritorial, así como los gastos de igual naturaleza previstos en sus respectivos presupuestos por los Organismos Autónomos del Estado y de las transferencias de capital efectuadas por el Estado y los Organismos Autónomos en favor de las entidades locales con destino a proyectos de inversión. Por ello puede sostenerse que la dotación del Fondo de Compensación Interterritorial es una consecuencia de la misma política económica que inspira el resto de las consignaciones previstas en el presupuesto para financiar inversiones públicas.

En cuanto a la posibilidad de que la cuantía del Fondo resulte afectada por la indisponibilidad de una parte del mismo que no supere el $10 \%$ del total, según permite el art. 57.1.b.) de la Ley General Presupuestaria en atención a la coyuntura económico-social, no existe en dicha Ley precepto alguno de donde pueda deducirse la inaplicabilidad de aquel artículo a las partidas destinadas al Fondo. Es cierto que la Exposición de Motivos de la Ley de 31-3-1984 alude a la finalidad de "desvincular la cuantía del Fondo de Compensación de las vicisitudes que pueda experimentar la estructura presupuestaria del Estado", pero ello no conduce a una desvinculación de dicha dotación presupuestaria de la disciplina general a que se sujetan los Presupuestos Generales del Estado, sino a que su cuantía, que el art. 2 de dicha Ley determina en un porcentaje de la inversión pública prevista, no puede ser alterada por el eventual asentamiento de las partidas que la integran en los Presupuestos Generales del Estado, a cuyo efecto su art. 3 define en términos materiales lo que debe entenderse por inversión pública. Precisamente la relación entre la cuantía de las inversiones públicas y la del Fondo de Compensación abona el criterio de la modificación de ésta última cuando, en uso de las facultades concedidas por el art. 57.1.b.) de la Ley General Presupuestaria se declare la no disponibilidad de los créditos consignados para finalizar aquéllas, pues de otro modo se rompería la proporción que la Ley establece entre unas y otras.

SEXTO: Se opone también la Comunidad recurrente a la alteración de la cuantía del Fondo de Compensación con base en el art. 57.1.b.) de la Ley General Presupuestaria, alegando que dicho precepto puede afectar a los créditos que figuren en los Presupuestos Generales del Es- 
tado en cuanto que éstos representan autorizaciones del Estado para contraer obligaciones cuyo importe no supere las cifras consignadas en ellos pero no para lo que representa, como es el Fondo de Compensación, pues son obligaciones exigibles al Estado desde el momento mismo de su inclusión en los Presupuestos, como resulta del art. 16 de la Ley Orgánica de Financiación de las Comunidades Autónomas, en el que se distinguen dos planos que pueden apreciarse en el Fondo de Compensación, el de su dotación en los Presupuestos Generales del Estado que tiene la misma naturaleza que las demás consignaciones presupuestarias del Estado de gastos y su distribución entre las distintas Comunidades Autónomas que corresponde a las Cortes Generales, conforme al art. 74.2 de la Constitución.

El art. 158.2 de la Constitución que impone la formación del Fondo de Compensación con el fin de corregir desequilibrios económicos interterritoriales y de hacer efectivo el principio de solidaridad, estableció que su destino serían los gastos de inversión de las Comunidades Autónomas y Provincias, en su caso, y que su distribución se realizaría por las Cortes Generales, estableciendo en su art. 74.2 el procedimiento para tomar respecto de ello la decisión que correspondiese y el art. 16.1 de la Ley Orgánica de Financiación de las Comunidades Autónomas establece los criterios generales de distribución de la dotación del Fondo de Compensación Interterritorial y remite a las Cortes Generales, conforme el art. 74.2 de la Constitución, para su distribución. Sin embargo dicha atribución no ha dado lugar a acuerdos anuales tomados por las Cortes Generales, conforme al art. 140 del Reglamento del Senado, sino, como ya hemos señalado antes, a una Ley, la 7/1984, de 31 de Marzo, en la que se concretan los criterios para la distribución del Fondo, para la elección de los proyectos de inversión a que ha de destinarse, y, por lo que interesa para el presente recurso, se impone la indicación a los Presupuestos Generales del Estado no sólo de la cuantía global del Fondo, sino de su distribución entre las distintas Comunidades Autónomas beneficiarias con relación expresa de los proyectos de inversión que competen a cada Administración y de los concurrentes (art. 7.2). La elección de este sistema de distribución del Fondo significa la habilitación al Gobierno para los actos de gestión del mismo, en los términos previstos para la elaboración de los Presupuestos Generales, con el parámetro del control añadido que supone su sumisión a los límites materiales que resulten de la Ley 31-3-1984, pero no implican por ello una alteración de la naturaleza que la inserción del Fondo de Compensación Interterritorial determina. Las consignaciones contenidas en el estado de gastos de los Presupuestos Generales significan autorizaciones para que la Administración pueda contraer obligaciones cuyo importe no supere esta suma, pero no obligaciones directamente exigibles 
cuya fuente se encuentra, como declara el art. 42 de la Ley General Presupuestaria, en la Ley, en los negocios jurídicos y en los actos o hechos que, según el derecho, las generen y esta misma naturaleza ha de reconocerse a las dotaciones del Fondo de Compensación Interterritorial. La competencia constitucional de las Cortes Generales con relación al Fondo de Compensación se refiere a la distribución del mismo entre los territorios beneficiarios, pero no a la determinación de su cuantía, por lo que la adopción del acuerdo de distribución no prejuzga la alteración del mismo posterior, en los límites que impone el art. 57.1.b) de la Ley General Presupuestaria, si el acuerdo de distribución se rectifica conforme a los mismos criterios de proporcionalidad que guiaron el primero.

No se opone a esta tesis, sino que la confirma, el hecho de que las dotaciones del Fondo de Compensación Interterritorial correspondientes a cada Comunidad Autónoma figuren en los Presupuestos de éstas como ingresos al tener el carácter de carga general del Estado, a los efectos previstos en los arts. 2, 138 y 158 de la Constitución, como declara el art. 4.2.b) de la Ley Orgánica de Financiación de las Comunidades Autónomas: el principio de solidaridad que consagran los preceptos constitucionales mencionados no se desconoce si la no disponibilidad acordada afecta en la debida proporción a todas las Comunidades Autónomas beneficiarias y la inclusión por éstas de la dotación del fondo en las correspondientes partidas de ingresos de sus presupuestos no significa su inmediata exigibilidad al Estado. El art. 21.3 de la Ley de Financiación de las Comunidades establece que los Presupuestos de las Comunidades Autónomas serán elaborados con criterios homogéneos, de forma que sea posible su consolidación con los Presupuestos Generales del Estado.

Ha de reconocerse que frente a las restantes partidas del Estado de gastos de los Presupuestos Generales del Estado, la del Fondo de Compensación Interterritorial tiene singularidades derivadas de su afectación finalista y de la vinculación que para la Administración del Estado supone la observancia de los criterios impuestos por la Ley de 31-31984, pero dentro de esos límites, no está excluida la posibilidad de actuar sobre dicha dotación en función de criterios coyunturales, al amparo de lo dispuesto en el art. 57.1.b) de la Ley General Presupuestaria.

SEPTIMO: La Comunidad recurrente alega la inalterabilidad de las dotaciones del Fondo de Compensación una vez consignadas en los Presupuestos Generales del Estado, desde el punto de vista del ejercicio de las competencias que corresponden a esa Comunidad, alegando que los Acuerdos del Consejo de Ministros no afectan al gasto propio sino 
JURISPRUDENCLA

al gasto ajeno, modificando indirectamente las previsiones presupuestarias adoptadas por los Parlamentos de las distintas Comunidades Autónomas, lo que interviene en su autonomía financiera. Conviene distinguir, a estos efectos la distinta incidencia que el art. 57.1.b) de la Ley General Presupuestaria produce en el Acuerdo del Consejo de Ministros de 12-5-1989 que se basa en aquel precepto y en el de 28-4-1989 que se adopta conforme al art. 67 de la misma Ley.

El art. 57.1 de la Ley General Presupuestaria atribuye al Gobierno dos medidas de signo opuesto para utilizar según aconseje la coyuntura económico-social: a) la posibilidad de disponer de un crédito de acción coyuntural que se incluirá en el Presupuesto del Estado para programas de inversión y b) la de no disponer hasta de un 10\% como máximo de los créditos para operaciones de capital que figuren en los Presupuestos del Estado y de los Organismos Autónomos del respectivo ejercicio. Por lo que se refiere a ésta última, que es la que se ha empleado en el Acuerdo del Consejo de Ministros de 12-5-1989, en nada afecta a la autonomía financiera de la Comunidad recurrente, porque desde la perspectiva de sus ingresos presupuestarios ya se ha razonado acerca de la necesaria coordinación de éstos con los Presupuestos Generales del Estado, y desde la de los gastos los proyectos de inversión que han de financiarse con el Fondo de Compensación Interterritorial tiene unos mecanismos de individualización que establece el art. 7 de la Ley de 31-3-1984, que no resultan alterados por la reducción de las dotaciones del fondo si no es por el inevitable abandono de los proyectos situados en los últimos lugares del orden de preferencia en que han de ser presentados, según el párrafo 3 del citado artículo. Y como éstos son los motivos alegados en contra del Acuerdo del Consejo de Ministros de 12-5-1989, debe de ser desestimado en este punto concreto el presente recurso.

OCTAVO: En cambio, el acuerdo del Consejo de Ministros de 28-41989 , tiene una causa y una finalidad diferentes: no pretende actuar contra las tendencias inflacionistas observadas por el Gobierno en la evolución de la coyuntura económica, sino allegar recursos para sufragar el coste que representa la articulación de las medidas previstas en el Real Decreto-Ley 3/1989, acudiendo para ello al mecanismo de las transferencias de crédito que autoriza el art. 67.2 de la Ley General Presupuestaria, lo que impone, en primer lugar, la reducción de los créditos de determinadas secciones de los Presupuestos Generales del Estado para 1989, entre ellas las que correspondían al Fondo de Compensación Interterritorial y su transferencia a la aplicación correspondiente al "crédito destinado a reasignar la financiación del coste de las medidas de carácter social". 
El control parlamentario de los Presupuestos Generales del Estado comprende no sólo la aprobación del importe global de los créditos cuya distribución se permite al Gobierno, sino la determinación concreta de las atenciones a que han de destinarse, tal como resulta del art. 59 de la Ley General Presupuestaria que establece que "los créditos para gasto se destinarán exclusivamente a la finalidad específica para la que hayan sido autorizados por la Ley Presupuestaria". Sin embargo, los inconvenientes que se derivan de una rígida interpretación del principio de especialidad cualitativa en un conjunto de previsiones tan complejo como es el que se plasma en las Leyes Anuales de Presupuestos, aconsejan ciertas modulaciones del mismo, que se llevan a cabo mediante transferencias de créditos presupuestarios para hacer frente a finalidades diferentes de las estrictamente consignadas en los Presupuestos Generales del Estado. Tal posibilidad, en cuanto excepción a un principio de gran tradición en el Derecho Presupuestario se configura con un marcado carácter limitativo, definiéndose en la Ley General Presupuestaria los supuestos de hecho que permiten su utilización, y las garantías para que su ejercicio no desvirtúe el sentido del mandamiento general contenido en el art. 59 anteriormente citado. En este sentido, el Real Decreto-Ley 3/1989, de 31 de Marzo, no habilitó al Gobierno de facultades distintas de las ya reconocidas en la Ley General Presupuestaria, ni supuso alteración de ésta, salvo en declarar aplicables a las modificaciones presupuestarias a realizar las limitaciones contenidas en el art. 70 de esta última Ley, por lo que las transferencias de créditos determinadas por la necesidad de financiar las medidas acordadas por aquella disposición legislativa habrán de someterse a las previsiones de la Ley General Presupuestaria, como el propio Acuerdo del Consejo de Ministros reconoce al invocar expresamente el art. 67.2 de dicha Ley, que establece que el Consejo de Ministros, a propuesta del de Economía y Hacienda, podrá autorizar las transferencias de crédito de las dotaciones no utilizadas en los programas de las distintas secciones del presupuesto, a los distintos conceptos del programa imprevistos y funciones no clasificadas, habilitando a tal efecto los créditos que sean necesarios, para su ulterior reasignación.

Por lo tanto, el presupuesto de hecho para la realización de esta transferencia consiste en la existencia de dotaciones presupuestarias que no se hayan utilizado en los programas de las distintas secciones del presupuesto. Independientemente de que el precepto no consagre la omnímoda potestad del Gobierno para ejecutar o no determinados programas previstos en los Presupuestos Generales del Estado a fin de transferir sus dotaciones a otros según su conveniencia, resulta claro que los programas afectados habrán de corresponder a aquéllos cuya ejecución sea consecuencia de una decisión exclusiva del Gobierno, por 
JURISPRUDENCIA

lo que no puede ser aplicado a los proyectos de inversiones financiados a través del Fondo de Compensación Interterritorial, cuya determinación, conforme el art. 7.1 de la Ley de 31-3-1984 es el resultado de un acuerdo entre la Administración Central del Estado y la correspondiente Comunidad Autónoma.

Confirma este criterio el art. 12 de dicha Ley que contiene un precepto radicalmente incompatible con la posibilidad de transferir dotaciones presupuestarias del Fondo de Compensación Interterritorial no utilizadas, a créditos distintos del Presupuesto, ya que expresamente se declara que los remanentes de créditos no comprometidos, correspondientes a proyectos de inversión financiados con cargo a la dotación del Fondo de Compensación Interterritorial asignada a una Comunidad Autónoma, se incorporan en el ejercicio inmediato posterior a los créditos del Fondo de Compensación de esa Comunidad Autónoma. Por ello, los citados acuerdos del Consejo de Ministros, en cuanto afectan a la Comunidad Valenciana que autorizan la transferencia impugnada, han de ser anulados por no ser conformes con el Ordenamiento Jurídico, desestimando en cambio el recurso en cuanto al Acuerdo del Consejo de Ministros de 12-5-1989.

NOVENO: La siguiente minoración que afecta a la Comunidad Valenciana se refiere a su participación, para 1989, en los ingresos del Estado, y lo es en una cuantía de 1.195.600.000 pesetas, que dejó de percibir. Frente a las alegaciones de la Comunidad Valenciana, se razona por el Consejo de Ministros, que el importe en dicha participación, para 1989, era una cantidad igual a la financiación de cada Comunidad Autónoma en 1986, incrementada en la misma medida que el "gasto equivalente del Estado" en el período 1986-1989, siendo el "gasto equivalente" el gasto presupuestado por los Departamentos Ministeriales que traspasaron servicios a las Comunidades Autónomas por los Capítulos de Personal, compra de bienes corrientes, e Inversiones reales, de donde resulta que la participación de las Comunidades Autónomas en los ingresos estatales crece igual que el gasto y por el contrario, en caso de reducción del Presupuesto estatal, que implique una disminución del índice de crecimiento del "gasto equivalente del Estado" ello supone la disminución de la participación de las Comunidades Autónomas en los ingresos del Estado.

Frente a estos argumentos, conviene precisar que la participación de las Comunidades en los impuestos del Estado es uno de los conceptos que constituyen las Haciendas de las Comunidades Autónomas, según el art. 4.e) de la Ley Orgánica de Financiación de las Comunidades Autónomas. En segundo lugar, que el art. 13 de la citada Ley dispone 
que esa participación de las Comunidades en los impuestos del Estado se fijará de la forma y por el procedimiento establecido en la Disposición Transitoria Primera de esa Ley Orgánica, es decir con la intervención de una Comisión Mixta paritaria Estado-Comunidad Autónoma, siendo necesario en todo caso, que el porcentaje de la participación, se fije por norma con rango de ley. Estos preceptos se reflejan en los arts. 51.e) y 53 del Estatuto para la Comunidad Valenciana de 1-7-1982, con la particularidad de que se trata de normas contenidas no en una, sino en dos Leyes Orgánicas, con las singularidades que en cuanto a las mayorías para su aprobación, modificación o derogación exige el art. 81 de la Constitución, y que por lo tanto las hacen invulnerables frente a normas dictadas sin esas mayorías, o sin rango de Ley Orgánica; aparte de ello, si el porcentaje de participación se fija por una Comisión paritaria Estado-Comunidad Autónoma; si los porcentajes de cada Comunidad solamente pueden ser revisados por unas causas concretas, enumeradas taxativamente en el art. 13 de la Ley Orgánica de Financiación de forma tasada - "únicamente podrá ser objeto de revisión" dice el precepto citado - si, además, el propio Acuerdo del Consejo de Ministros de 16-3-1990 resolviendo el recurso de reposición interpuesto contra los de 28 de Abril y 12 de Mayo de 1989, reconoce en su Considerando Cuarto que el método para la aplicación del Sistema de Financiación de las Comunidades Autónomas, aprobado el 7-11-1986, lo fue para el quinquenio 1987-1991, es evidente que la modificación operada por los Acuerdos del Consejo de Ministros adolece de una falta de motivación, mediante la invocación de alguno de los supuestos que menciona el art. 13 de la Ley Orgánica de Financiación, se toma unilateralmente por uno de los componentes de la Comisión paritaria, modifica variándolo, un porcentaje que debe de tener una duración determinada, y afecta a dos normas con rango de Ley Orgánica, como son la de Financiación de las Comunidades Autónomas y el propio Estatuto de Autonomía, por lo que al igual que antes se hizo, debe de anularse en este particular, por no ser conforme con el Ordenamiento Jurídico.

(Sentencia de 7 de noviembre de 1992. Ar. 1129. Ponente: L. L. Martín Herrero).

\section{ORGANIZACION ADMINISTRATIVA}

1. Distribución de competencias en materia de organización municipal. Art. 20 de la LBRL. Orden de prelación entre la ley autonómica y los reglamentos orgánicos municipales. Potestad de autoorganización por acto singular. Creación de Comisiones de Asesoramiento. 
JURISPRUDENCIA

\section{FUNDAMENTOS DE DERECHO}

SEGUNDO: Los arts. 137 y 140 de la Constitución (RCL 1978, 2836 y ApNDL 2875) garantizan la autonomía de los Municipios para la gestión de sus intereses y diseñan los rasgos esenciales de su organización, sobre la que se ha pronunciado el Tribunal Constitucional en numerosas resoluciones (SS. 4/1981; 32/81;84/82; 32/85; 27/87; 259/88; $214 / 1989$.

La Sentencia del Pleno del Tribunal Constitucional de 21-12-1989 (S. 214/1989) ha declarado (F. $6^{\circ}$ ) que, en materia de organización municipal, el orden constitucional de distribución de competencias se funda en la existencia de tres ámbitos normativos diferentes correspondientes a la legislación básica del Estado (art 149.1.18 $\mathrm{CE}$ ), la legislación de desarrollo de las Comunidades Autónomas, según los respectivos Estatutos, y la potestad reglamentaria de los municipios, inherente ésta última a la autonomía que la Constitución garantiza en su artículo 140. Es claro que la potestad de autoorganización municipal -art. 4.1 a) LRBRL_, se ejerce en el marco de los límites establecidos en la legislación básica estatal y en las legislaciones de desarrollo de las Comunidades Autónomas que no pueden, no obstante, invadir ni desconocer la potestad de autoorganización que la Constitución garantiza a la instancia municipal.

TERCERO: El art. 20 de la Ley de Bases de Régimen Local distingue (tras la S. 214/1989 citada) entre órganos que han de existir necesariamente (Ayuntamiento, Pleno, Alcalde, Tenientes de Alcalde y, en su caso, Comisión de Gobierno) y órganos complementarios, que establecen las leyes de las Comunidades Autónomas y el Reglamento Orgánico de cada Municipio. La declaración de inconstitucionalidad sobrevenida del citado art. 20 de la Ley Básica estatal no plantea en el caso problema para la determinación del Derecho aplicable. Cierto es que la referida S. 214/1989 ha modificado el orden de prelación entre Ley autonómica y los Reglamentos Orgánicos Municipales que resultaba de la redacción que presentaba la Ley 7/1985 en el momento en que se dictó el acto administrativo que enjuiciamos, pero dicha circunstancia es irrelevante para la resolución de la cuestión aquí planteada. Aparte de que los Jueces y Tribunales estamos obligados a no aplicar una norma ya declarada inconstitucional, aunque la sentencia de declaración de inconstitucionalidad sea posterior al acto impugnado, en este caso la cuestión carece de relieve por cuanto no se ha invocado ni resulta la existencia de Reglamento Orgánico en el Ayuntamiento de San Bartolomé de Tirajana. El citado Ayuntamiento ha creado las Comisiones que se enjuician por un acto de autoorganiza- 
ción, por lo que el problema a resolver se ha reducido, y se reduce con independencia de la STC 214/1989-a determinar si dichas Comisiones respetan los límites establecidos tanto en la Ley 7/1985 como en la Ley autonómica 8/1986 a la potestad de autoorganización por acto singular del Municipio afectado.

CUARTO: La Ley 8/1986, de 18 de Noviembre, de Régimen Jurídico de las Administraciones Públicas de Canarias establece, en su art. 57.1, diversos órganos complementarios para el estudio, asesoramiento, consulta, propuesta y seguimiento de la gestión municipal. Se regulan así las Comisiones Municipales Informativas, la Comisión Especial de Cuentas, la Comisión de Colaboración con otras Administraciones Públicas "y cualesquiera otras que pudieran crear el Pleno de la Corporación". Es necesario determinar si se pueden encuadrar en este último apartado las Comisiones de Asesoramiento en litigio, ya que el Ayuntamiento apelante aduce el inciso últimamente citado como título habilitante para la creación de las mismas.

QUINTO: Un examen de la regulación de los órganos complementarios de los Municipios canarios (arts 78 a 85 de la Ley autonómica 8/86) permite apreciar que la libertad de crear cualesquiera otras Comisiones concedida a la potestad de autoorganización municipal se refiere exclusivamente a las Comisiones Especiales y no a las Comisiones permanentes y de ámbito general, o, en otro término, Comisiones Municipales Informativas. En tal sentido el inciso final del art. 57.1. b) de la Ley -que se invoca- debe interpretarse en relación directa con el art. 82 de la misma Ley que dispone que "los Ayuntamientos podrán acordar la creación de Comisiones Especiales por acuerdo de la mayoría absoluta del Pleno a propuesta del Alcalde o de la cuarta parte del número legal de Concejales". Y no puede aducirse con éxito que las Comisiones que se examinan son Comisiones especiales ya que la Ley 8/1986 de la Comunidad canaria mantiene claramente la distinción que también se aprecia en la normativa estatal contenida en el Reglamento de Organización, Funcionamiento y Régimen Jurídico de las Corporaciones Locales (RD $2586 / 1986$, de 28 de Noviembre). Dicha regulación estatal, aquí sólo de valor supletorio (art. 149.3 CE), mantiene un esquema organizativo básico que se remonta en nuestro Derecho a la Ley Orgánica municipal de 2-10-1877. Distinguió ya dicha Ley (arts 60 y 61 ) entre Comisiones permanentes, que se caracterizaban por este carácter y porque entre ellas se repartían todos los negocios generales a cargo del Ayuntamiento, y las Comisiones especiales que cesaban una vez concluido su encargo. Este sigue siendo hoy el criterio que diferencia, en el vigente Derecho estatal, dentro del género de las Comisiones informativas entre Comisiones informativas permanentes "que se constituyen con carácter gene- 
JURISPRUDENCLA

ral, distribuyendo entre ellas las materias que han de someterse al Pleno" (art. 124.2 ROFRJCL) y Comisiones informativas especiales "que el Pleno acuerde constituir para un asunto concreto" y que "se extinguen automáticamente una vez hayan dictaminado o informado" "salvo que el acuerdo plenario que las creó dispusiera otra cosa" (art. 124.3 ROFRJCL). La Ley 8/1986, de las Administraciones Públicas de Canarias mantiene, como queda dicho, la misma distinción (arts 80, 78.3 "a contrario" y 84).

SEXTO: La verdadera naturaleza de las Comisiones de Asesoramiento creadas en el acto impugnado, queda claramente desvelada al configurarse como órganos permanentes de asesoramiento y que se reparten todas las materias esenciales de competencia municipal por lo que es claro que no se trata de Comisiones Especiales sino de Comisiones Municipales Informativas, que suponen una duplicidad respecto de las que - se dice - ya existen con tal nombre en el propio Ayuntamiento. $\mathrm{Y}-\mathrm{con}$ independencia de que, como se razona, pudieran tal vez disponer de cierto espacio de actuación respecto de las competencias de la Alcaldía o de las que no respeten el principio de proporcionalidad (art. 20.3 de la Ley 7/1985) que, como se aduce por el Ayuntamiento apelante, no sería imperativo caso de no conocer de asuntos de la competencia del Pleno- es claro que las mismas son ilegales porque la Ley 8/1986 no autoriza - con las características enunciadas de órganos complementarios permanentes de asesoramiento de ámbito generalque se creen en los Municipios canarios otras Comisiones que las Municipales Informativas que desarrolla en sus arts. 78 a 81, por lo que la creación de las Comisiones de Asesoramiento por el acto impugnado excede de las potestades de autoorganización municipal que establece la Ley de Régimen Jurídico de las Administraciones Públicas de Canarias de 18-11-1986 - sin que se hayan planteado o sean de plantear dudas sobre la adecuación a la Constitución del margen que la citada Ley concede a la potestad municipal de autoorganización- por lo que procede declarar la nulidad del acto impugnado y contrarias a Derecho las Comisiones creadas en él.

(Sentencia de 9 de febrero de 1993. Ar. 548. Ponente: J. RodríguezZapata Pérez).

\section{HACIENDAS LOCALES}

1. Aprobación de Tarifas de suministro municipal de agua potable. Concurrencia de competencias entre la Administración Local y las Comunidades Autónomas. Doble naturaleza de las 
citadas tarifas: Ingresos de derecho público sometidos al régimen jurídico de las tasas, y precios públicos sometidos por ello a la normativa y competencias establecidas por las disposiciones reguladoras de la ordenación económica y su política de precios.

\section{FUNDAMENTOS DE DERECHO}

PRIMERO: Única cuestión a decidir en esta Segunda instancia es la referente a si la sentencia apelada es, o no, ajustada a Derecho en cuanto por la misma se estima el recurso contencioso-administrativo del caso y se anulan las resoluciones administrativas impugnadas, por las cuales se deniega la autorización correspondiente a las nuevas tarifas del suministro municipal de agua potable del Municipio de Betxí (Castellón).

Así conocido el tema objeto de la apelación, la resolución al mismo se hace depender de si, a efectos competenciales para su aprobación, las tarifas del suministro municipal del caso merecen: o bien el calificativo legal de "tasa" (como sostiene el Ayuntamiento apelado), o ya el de precio (como afirma la Comunidad Autónoma apelante); pues bien, a los efectos de la competencia que ahora exclusivamente interesan, las tarifas del caso, independientemente de que es bien cierto que constituyen un ingreso de Derecho Público sometido al régimen jurídico propio de las tasas y por ello exaccionables por la vía de apremio (art. 155.1 del Reglamento de Servicios de las Corporaciones Locales, de 17 Junio de 1955, art. 8.2 del Reglamento de Haciendas Locales de 4-8-1952, en relación con los arts 14 y 19.21 del Real Decreto 3250/1976, de 30 de Diciembre; arts 199.2, 207 y 212.21 del Real Decreto Legislativo 781/1986, de 18 de Abril, entre otros preceptos), no lo es menos que en dichas tarifas concurre, en cuanto regulan una contraprestación pecuniaria a satisfacer por un bien o servicio que se adquiere o se utiliza, en su caso, la cualidad de precio, y por ello sometido a la normativa y competencias establecidas por las disposiciones reguladoras de la Ordenación Económica y su política de precios, como se encarga de especificar el art. 10.3 del Decreto Ley núm. 12/1973, de 30 de Noviembre sobre "Ordenación Económica: medidas coyunturales", y aun más concretamente toda la normativa que luego especifica qué bienes y servicios quedan sometidos al régimen de "Precios autorizados", como desarrollo del Real Decreto 2695/1977 de 28 de Octubre, en materia de precios, cuando se incluye en tal categoría: "Agua (abastecimiento a poblaciones)", así a manera de ejemplo: Anexo 3 de calendado Real Decreto 28-10-1977; Anexo 3 de la OM 14-10-1980; Anexo 3 de la OM 2810-1981; de tal modo que en relación con las tarifas del caso y en el as- 
pecto competencial de su aprobación, concurre una doble naturaleza: la de tasa, por una parte y la de precio por otra; sin que ambos calificativos sean incompatibles entre sí al obedecer uno y otro a diferentes objetivos o finalidades públicas que determinan una situación de concurrencia o yuxtaposición de competencias atribuidas a poderes distintos: la tarifaria a la Administración Local y la de política de precios a la Comunidad Autónoma del caso, tal como lo tiene entendido el Tribunal Constitucional en su Sentencia núm. 53/1984, de 3 de mayo (Fundamento Jurídico Segundo "ab initio"); alcanzada la presente conclusión, al no poder negarse la competencia en el caso de Autos a la Generalidad Valenciana, atendidas sus potestades en política de precios, de ahí que al ser tal cuestión el único punto objeto de controversia en el presente litigio, a virtud de lo dicho, no es de aplicación al caso el art. 47.1.a) de la Ley de Procedimiento Administrativo, derivándose de ello la estimación de la apelación y la correspondiente revocación de la sentencia apelada, con la paralela declaración de ser conformes a Derecho las resoluciones administrativas objeto del recurso jurisdiccional, en cuanto al único motivo impugnatorio de las mismas al presente objeto de atención.

(Sentencia de 21 de enero de 1993. Ar. 393. Ponente: A. Galán Menéndez).

\section{EMPLEO PUBLICO}

1. Real Decreto 1174/1987 sobre régimen jurídico de los funcionarios de la Administración Local con habilitación de carácter nacional. Delegación de funciones de fe pública y asesoramiento legal. Nombramiento de Jefe de División de Secretaría y Servicios Generales de Distrito en favor de funcionario con categoría de Técnico de Administración General.

\section{FUNDAMENTOS DE DERECHO}

QUINTO: Impugna directamente la recurrente el art. 13.2 del Real Decreto 1174/1987, de 18 de Septiembre, que aprueba el Régimen Jurídico de los funcionarios con habilitación de carácter nacional, a cuyo tenor "las funciones de fe pública y asesoramiento legal preceptivo, recogidas en los arts. 2 y 3 y concordantes de este Real Decreto, respecto de Juntas, Órganos o Entidades, dependientes de la Corporación distintas del Alcalde, Pleno o Comisión de Gobierno decisoria, podrán ser encomendadas por la Corporación a funcionarios propios de la misma carentes de la habilitación de carácter nacional, a propuesta del Titular 
de la Secretaría y, que actuarán como delegados de éste", pues entiende la recurrente que dicho precepto infringe el art. 92.3 de la Ley $7 / 1985$ de 2 de Abril, Reguladora de las Bases de Régimen Local, al disponer este precepto que "son funciones públicas necesarias en todas las Corporaciones Locales, cuya responsabilidad administrativa está reservada a funcionarios con habilitación de carácter nacional: a) la de Secretaría, comprensiva de la fe pública y el asesoramiento legal preceptivo", lo que lleva a la recurrente a sostener, que en base a este último precepto de rango jerárquico superior a aquel Real Decreto, todas las Secretarias de Distrito del Ayuntamiento de Barcelona, deben estar dotadas de un Secretario con habilitación de carácter nacional, al que están reservadas por Ley aquellas funciones de fe pública y asesoramiento legal preceptivo, por lo que el nombramiento que impugna, recaído en persona, carente de habilitación de carácter nacional, debe anularse, aunque tenga la cobertura de aquel Real Decreto 1174/1987, ya que el art. 13.2 del mismo infringe lo dispuesto en norma de rango jerárquico superior.

Sin embargo, no podemos acoger dicha argumentación. Cierto es, que en la legislación anterior a la Ley 7/1985, de 2 de Abril, el Decreto 3046/1977, de 6 de Octubre que aprobó el Texto Articulado Parcial de la Ley 41/1975, de Bases del Estatuto de Régimen Local, en su art 84, establecía que: "en los municipios con población superior a 500.000 habitantes que tengan establecidos Distritos administrativos, las Secretarías de éstos, o en su caso, de Zonas, serán desempañadas por funcionarios pertenecientes a la Primera Categoría del Cuerpo nacional de Secretarios de la Administración Local. Para al nombramiento de tales Secretarios de Distrito o Zona será aplicable lo dispuesto en el núm. 3 del art. 81" (esto es, sistema de concurso o concurso-oposición). Precepto similar al transcrito se contenía también en el art. 233 del Reglamento de Funcionarios de la Administración Local, aprobado por Decreto de 30-5-1952. Pero ni en la Ley 7/1985, de 2 de Abril, ni en el Real Decreto Legislativo 781/1986, de 18 de Abril, por el que se aprueba el Texto Refundido de las disposiciones legales vigentes en materia de Régimen Local, encontramos un precepto similar al art. 84, del Texto Articulado Parcial de la Ley 41/1975, Ley ésta que, además, resultó expresamente derogada, por la Disposición Derogatoria del Real Decreto Legislativo 781/1986. Antes al contrario, en el art. 161 de este último Real Decreto Legislativo, sólo se exige que en todas las Entidades Locales exista al menos un puesto de trabajo que tenga atribuida la responsabilidad administrativa de la función a que se refiere el ar. 92.3 a) de la Ley 7/1985, de 2 de Abril (con la salvedad de agrupación de Municipios o Entidades Locales a efectos de sostenimiento en común de dicho puesto de trabajo, o de aquellos Municipios o Entidades Locales que 
carezcan de medios para sostenerlo), disponiendo el art. 165 del mismo Texto que las Corporaciones, en los términos que reglamentariamente se determinen por la Administración del Estado, "podrán" crear otros puestos de trabajo reservados igualmente a funcionarios que posean dicha habilitación, cuya provisión se ajustará, en todo caso, al sistema previsto en el art. 99 de la Ley 7/1985. Se faculta, por lo tanto, pero no se impone a la Corporación la creación de más de un puesto de trabajo para las funciones a que hace referencia el art. 92.3 a) de la Ley 7/1985. Y si en el Municipio de Barcelona existe un Secretario general de la Corporación con habilitación de carácter nacional -extremo éste no controvertido- en él está residenciada la responsabilidad administrativa de las funciones a que hace referencia el art. 92.3.a) de la tan repetida Ley $7 / 1985$, sin que el hecho de que dicha Corporación, en uso de sus facultades de autoorganización - art. 4.1.a) de la ley 7/1985-en sesión de 512-1986 del Consejo Plenario del Ayuntamiento aprobara las Normas Reguladoras de la Organización de los Distritos - directamente aplicables a tenor del art. 5 A de la Ley 7/1985- obligue a dicho Ayuntamiento, a dotar a cada Distrito de un Secretario con habilitación de carácter nacional, pues en la Disposición Transitoria Segunda de dichas Normas se establece "que el Secretario general e Interventor ejercerán sus funciones de la fe pública, asesoramiento legal y control y fiscalización interna de la gestión financiera de los Consells de Distrito... sin perjuicio de la posibilidad de delegar las mencionadas funciones", delegación esta que asimismo aparece autorizada en el impugnado art. 13.2 del Real Decreto 1174/1987, de 18 de Septiembre, a favor de funcionarios propios de la Corporación carentes de habilitación nacional, sin que ello comporte infracción del art. 93.2 de la Ley 7/1985, pues este último precepto se limita a reservar la "responsabilidad administrativa" derivada de las funciones indicadas en el mismo a los funcionarios con habilitación nacional, por lo que en caso de delegación "a propuesta del titular de la Secretaría" - delegación ésta no prohibida en la Ley- el Secretario sigue manteniendo su responsabilidad administrativa por el resultado de la actuación del delegado, vistos los efectos formales de la delegación.

Resta, por último, recordar que la propia apelante ya pretendió la invalidez, por vía de impugnación indirecta, de las normas municipales relativas a la organización de los Distritos de Barcelona, y de la Norma contenida en el art. 13.2 del Real Decreto 1174/1987, siendo desestimado su recurso en Sentencia de la extinta Audiencia Territorial de Barcelona de 17-2-1989, sentencia que ha sido confirmada en reciente Sentencia de esta Sala Tercera de fecha 24-11-1992.

A mayor abundamiento, bastaría para rechazar la impugnación directa que la recurrente hace del art. 13.2 del Real Decreto 
1174/1987, con citar la Sentencia de esta misma Sala Tercera, de fecha 4-12-190, recaída en recurso directo interpuesto por la Asociación Sindical de Secretarios, Interventores y Depositarios de la Administración Local, impugnando, entre otros, el referido art. 13.2 del precitado Real Decreto, sentencia en la que se desestimó el recurso interpuesto.

(Sentencia de 25 de febrero de 1993. Ar. 1191. Ponente: M. Murillo Martín de los Santos).

\section{SANCIONES}

1. Infracciones en materia de defensa de la producción agroalimentaria. Transferencia de competencias a las Comunidades Autónomas en materia de protección al consumidor.

\section{FUNDAMENTOS DE DERECHO}

TERCERO. La Sala, haciendo uso del art. 43.2 de la Ley de Jurisdicción, ha planteado a las partes el problema de determinar la eficacia que respecto de los acuerdos recurridos, tiene la transferencia de competencias en materia de disciplina de mercado efectuada a favor de la Comunidad Autónoma de Madrid, operada conforme al art. 28.4 del Estatuto de Autonomía de dicha Comunidad aprobado por la Ley Orgánica 3/1983, de 25 febrero y el Real Decreto 2376/1984, de 26 de diciembre. El análisis del problema de la competencia es previo al de cualquier otro, ya que, si el órgano administrativo que ha actuado en el procedimiento carece del requisito de competencia, el acto debe de anularse, para que conozca del mismo el órgano que resulte competente, que será el que habrá de pronunciarse sobre las cuestiones planteadas en el expediente.

CUARTO. En relación con el aludido problema de la competencia, debe de partirse de que, tal como expresa la Sentencia del Tribunal Constitucional de 4-10-1985, la distribución de competencias entre el Estado y las Comunidades Autónomas, deriva directamente de la Constitución y los Estatutos de Autonomía. El Estatuto de Autonomía de Madrid, aprobado por la Ley Orgánica 3/1983, de 25 febrero atribuye a dicha Comunidad, en los términos que establezcan las leyes y las normas reglamentarias que en desarrollo de su legislación dicte el Estado, la función ejecutiva en materia de comercio interior, defensa del consumidor y del usuario (art. 28.4). El Real Decreto $2376 / 1984$, de 26 diciembre, transfiere determinadas funciones que 
el Estado venía realizando en materia de disciplina de mercado. Según el sistema de distribución de competencias operado, la función ejecutiva de aplicar la potestad sancionadora en las infracciones relativas a la materia denominada disciplina de mercado radica en su integridad en la Comunidad Autónoma de Madrid, salvo en el supuesto en que por razón de la cuantía de la sanción a imponerse, la competencia decisoria corresponda al Consejo de Ministros, en cuyo caso el ejercicio de la potestad sancionadora se desdobla, entre la Comunidad Autónoma y el Estado, de modo que aquélla es la competente para tramitar el procedimiento sancionador en todas sus fases, incluida la propuesta de sanción, y éste, por medio del Consejo de Ministros, y con base en tal propuesta, dicta únicamente el acto de decisión final.

QUINTO. El Abogado del Estado se opone a que la materia a la que el presente proceso se refiere pueda entenderse que es objeto de transferencia a la Comunidad Autónoma de Madrid. Defiende, en síntesis, que un concepto es la materia de disciplina del mercado (hoy superado y sustituido por el de protección al consumidor) y otro bien distinto la producción agroalimentaria. La disciplina del mercado se actuó por el entonces Ministerio de Comercio, y hoy por el de Sanidad y Consumo; mientras que la producción agroalimentaria se actuó, desde antiguo, por el Ministerio de Agricultura, Pesca y Alimentación. Las infracciones en materia de defensa de la calidad de la producción agroalimentaria se encuentran reguladas en el art. 4 del Real Decreto 1945/1983, en aplicación del cual el Consejo de Ministros ha impuesto la sanción a que se refiere el presente recurso. Pues bien, en opinión del representante de la Administración, esta materia no ha sido objeto de transferencia a la Comunidad Autónoma de Madrid, sino que es una competencia mantenida por el Ministerio de Agricultura, Pesca y Alimentación, advirtiendo que el acuerdo anexo al Real Decreto 2276/1984, sólo alude a actuaciones realizadas a través del Ministerio de Sanidad y Consumo, pero no del de Agricultura, Pesca y Alimentación. La Sala entiende, que el problema así planteado, no puede resolverse atendiendo a una distribución de las competencias del Estado entre los distintos Departamentos ministeriales, sino definiendo y acotando cuál es la materia realmente transferida a la Comunidad Autónoma de Madrid. Como se ha dicho anteriormente, el Estatuto de Autonomía atribuye a esta Comunidad Autónoma la función ejecutiva en materia de defensa del consumidor. El art. 51 de la Constitución, en su apartado primero, señala que "los poderes públicos garantizarán la defensa de los consumidores y usuarios, protegiendo, mediante procedimientos eficaces, la seguridad, la salud y los legítimos intereses económicos de los mismos". Para desarrollar este precepto constitucional 
se promulgó la Ley 26/1984 de 19 de julio, General para la Defensa de los Consumidores y Usuarios, cuya disposición final segunda, declara aplicable, en materia de infracciones y sanciones, el Real Decreto 1945/1983. Esto quiere decir, que transferidas a la Comunidad de Madrid, las funciones atribuidas a la Administración del Estado respecto a las infracciones administrativas en materia de disciplina de mercado (con la propuesta, en su caso, al Consejo de Ministros), debe estimarse que se le han transferido las competencias relativas a las infracciones que se cometan dentro de su ámbito territorial en materia de defensa del consumidor, pues éste es el ámbito objetivo de sus facultades de acuerdo con el Estatuto de Autonomía. En el caso aquí enjuiciado, la infracción sancionadora consiste en el hecho de que en las muestras tomadas de una partida de $18.000 \mathrm{Kg}$. de queso de leche de oveja, en la fábrica que "Industrial Quesera Española S.A.", tiene establecida en Alcobendas (Madrid), Carretera de Madrid a Irún, Km. 15,400, del análisis practicado se desprende la presencia de leche de vaca y de cabra en la composición del mismo, constando en su etiquetado estar elaborado con leche de oveja exclusivamente. Por tanto, como el producto analizado objeto de infracción está destinado de modo directo al consumo humano, la Administración, al sancionar dicha infracción está protegiendo los legítimos intereses económicos del consumidor - art.51, ya mencionado de la Constitución y art. 2.1b) de la Ley General para la Defensa de Consumidores y Usuarios-. La materia ha de encuadrarse en el concepto "defensa del consumidor", sobre el que ejerce su competencia la Comunidad Autónoma de Madrid, según su Estatuto de Autonomía. En este sentido debe interpretarse la transferencia de competencias realizada por el Real Decreto $2376 / 1984$, de 26 de diciembre, independientemente, del precepto del Real Decreto 1945/1983, en que se incardine la infracción y del Departamento ministerial que haya instruido las actuaciones. En su virtud, la infracción descubierta en la elaboración de queso de oveja y la sanción impuesta en el caso enjuiciado son materias que se encuadran en el concepto de "defensa del consumidor", por lo que respecto a ella, tiene vigencia la transferencia de competencias realizada a favor de la Comunidad Autónoma de Madrid por el Real Decreto 2376/1984, de 26 diciembre, ya citado. En el mismo sentido, en relación con infracciones cometidas en la elaboración respecto de quesos de oveja, se han pronunciado ya las Sentencias de este Tribunal Supremo de 31 octubre y 12 noviembre 1991, lo que comporta el rechazo de las alegaciones a este respecto formuladas por el señor Abogado del Estado.

SEXTO. Expuesto lo anterior, se advierte que todo el expediente sancionador administrativo tramitado en las actuaciones, de las que se deriva el presente recurso, lo ha sido por órganos de la Administración 
JURISPRUDENCIA

del Estado, incluida la propuesta de sanción, sin que en ningún momento se produjese la actuación o intervención de Organos de la Comunidad Autónoma de Madrid, que era la competente para tramitar las actuaciones y formular propuesta de sanción, al hạberse cometido los hechos denunciados $\mathrm{u}$ objeto de recurso, en la provincia de Madrid. La infracción de las normas del Estatuto de Autonomía de Madrid y del Real Decreto 2376/1984 (de transferencias) determina la nulidad de actuaciones, pues aun cuando el acuerdo sancionador del Consejo de $\mathrm{Mi}$ nistros, no pueda ser considerado como un acto dictado con manifiesta incompetencia (art. 47.1 de la Ley de Procedimiento Administrativo), no es menos evidente que en el procedimiento se ha infringido el criterio esencial de distribución de competencias atinentes al ejercicio de la potestad sancionadora en materia de defensa del consumidor entre las Administraciones estatal y autonómica, encontrándonos, pues, ante un vicio procedimental, que aun como de simple anulabilidad, no sería susceptible de convalidación, como se desprende de la Sentencia del Tribunal Constitucional de 4-10-1985 y de las de este Tribunal Supremo de 31 de octubre y 12 de noviembre 1991, ya anteriormente citadas. Tampoco cabe entender que se ha producido una convalidación del vicio de incompetencia, conforme al art. 53.2 de la Ley de Procedimiento Administrativo, por no existir entre la Administración autonómica y la estatal la relación de jerarquía contemplada en dicha norma; todo lo cual conduce a la procedencia de estimar el recurso contencioso-administrativo interpuesto por la entidad mercantil "Industrial Quesera Española S.A." frente a los Acuerdos del Consejo de Ministros de 2820-2988 y 29-6-1990, y a declarar la nulidad de los mismos, a fin de que las actuaciones inspectoras, como actividad colaboradora de denuncia, sean remitidas a los órganos competentes de la Comunidad Autónoma de Madrid, para que se sustancie ante la misma el procedimiento sancionador correspondiente para depurar las posibles infracciones, hasta formular la eventual propuesta de resolución pertinente y, en su caso, dictarse la resolución final oportuna por el órgano competente para ello.

(Sentencia de 10 de enero de 1993. Ar. 19. Ponente: F.J. Hernando Santiago).

\section{RESPONSABILIDAD PATRIMONIAL}

1. Funcionamiento de servicio público. Velódromo municipal en desuso e incluso cerrado. Existencia de culpa "in vigilando". Falta de señalización prohibiendo la utilización de las instalaciones y el acceso a las mismas. Concurrencia de culpas. 
MARIA DEL ROSARIO ALONSO IBÁÑEZ

\section{FUNDAMENTOS DE DERECHO}

PRIMERO. La controversia a resolver en el presente proceso se refiere a un caso de pretendida responsabilidad patrimonial de un ente de la Administración Local, regulada en nuestro Derecho por el art. 54 de la Ley 7/1985, de 2 de abril, sobre las Bases del Régimen Local, el cual remite a la legislación general sobre responsabilidad administrativa siendo aplicables por tanto el art. 40 de la Ley de Régimen Jurídico de la Administración del Estado y sobre todo el art. 106.2 de la Constitución.

Reconocida la responsabilidad y otorgada la correspondiente indemnización por el Tribunal de instancia, el apelante se esfuerza en desvirtuar los Fundamentos Jurídicos de la sentencia apelada discutiendo que efectivamente se esté ante un caso de funcionamiento del servicio público y sobre todo negando el nexo de causalidad entre la conducta administrativa y el daño producido.

Para resolver sobre el proceso hay que examinar por tanto si se dan en el caso de autos los requisitos necesarios para apreciar la existencia de responsabilidad, tratándose en el supuesto estudiado de la lesión producida, el funcionamiento del servicio, y el antes citado nexo de causalidad. No obstante, respecto a la lesión no se plantea discusión procesal ninguna pues se desprende de los autos y así lo reconoce el Ayuntamiento, ante el Tribunal de instancia que el hijo del actor falleció en accidente, tratándose de verdadera lesión, efectiva, individualizada respecto a una persona, y económicamente evaluable al haber reconocido hace lustros la jurisprudencia de este Tribunal Supremo la evaluación de daños morales.

Hay que limitarse, por tanto, al estudio de los demás requisitos, a saber, el funcionamiento del servicio y el nexo de causalidad.

SEGUNDO. En cuanto al funcionamiento del servicio público, la Sala no puede acoger las alegaciones del Ayuntamiento apelante, el cual pretende que de la existencia del velódromo municipal donde se sufrió el accidente no se desprende que hubiera en funcionamiento servicio público alguno. El Ayuntamiento insiste en este extremo, tanto más cuanto que con anterioridad se había reconocido que las instalaciones eran deficientes, por lo que estaban en desuso e incluso cerradas, aunque el acceso a las mismas sin duda podía producirse como se produjo de hecho.

Ahora bien, lo cierto es que para que exista responsabilidad administrativa por las lesiones sufridas no es necesario que se trate de la 
JURISPRUDENCLA

existencia de un servicio público entendido en sentido estricto como una prestación ofrecida al público de forma regular y continuada, bastando que se trate de una actividad pública, con lo que viene a acogerse la acepción más general del concepto de servicio público.

En el caso de autos está fuera de duda que el fallecimiento por accidente ocurre en una instalación municipal cuya custodia y conservación corresponde al Ayuntamiento, base fáctica más que suficiente para plantearse si el estado de las instalaciones, e incluso las condiciones de acceso, dan lugar a una relación de causalidad entre la conducta municipal y el daño producido.

TERCERO. En cuanto al nexo de causalidad, la representación procesal del Ayuntamiento reitera el punto de vista manifestado en la primera instancia de que el accidente se produjo por culpa exclusiva del fallecido y afirma que para que se dé el nexo causal es necesario que la lesión sea consecuencia directa y exclusiva del funcionamiento del servicio.

Con ello no se desvirtúan los Fundamentos Jurídicos de la sentencia apelada, por cuanto dicha sentencia establece claramente que el Ayuntamiento no había instalado señalización ninguna prohibiendo la utilización de las instalaciones y no había tomado medidas eficaces para impedir el acceso a las mismas, extremos ambos que indican la existencia de una culpa in vigilando.

Por lo demás tampoco puede acogerse la alegación de que para que existiese responsabilidad, el accidente hubiera debido ocurrir como consecuencia exclusiva de la conducta del Ayuntamiento. Pues ya se desprende de la sentencia del Tribunal de instancia, en primer lugar que existió una culpa del fallecido, si bien el nexo de causalidad no se rompe por la concurrencia de culpas, y en segundo lugar que la culpabilidad de la víctima del accidente no es tan principal ni tan exclusiva que sea suficiente para eximir por completo de responsabilidad al Ayuntamiento.

Así lo aprecia también la Sala por cuanto el Ayuntamiento no había tomado medidas verdaderamente eficaces para impedir el acceso a las instalaciones, y no había hecho indicación ninguna sobre que estuviera prohibida su utilización. Por tanto hay que apreciar que existe una concurrencia de culpas, lo que conduce a confirmar la sentencia apelada.

(Sentencia de 28 de enero 1993. Ar. 422. Ponente: M. Baena del Alcázar). 
MARIA DEL ROSARIO ALONSO IBÁÑEZ

\section{BIENES PUBLICOS}

1. Dominio público marítimo-terrestre. Autorización de la Comunidad Autónoma para la instalación, explotación y funcionamiento de parques de cultivo de moluscos. La titularidad estatal del demanio no es en sí misma un criterio de delimitación competencial y en su consecuencia la naturaleza demanial no aisla a la porción de terreno de su entorno, ni la sustrae de las competencias que puedan corresponder a otros entes públicos. Configuración de la concesión demanial que implica obras fijas dentro del mar.

\section{FUNDAMENTOS DE DERECHO}

PRIMERO. Por Orden de 26-5-1989 la Consejería de Ganadería, Agricultura y Pesca de la Diputación Regional de Cantabria, otorgó autorización administrativa a la Sociedad Cooperativa de Trabajo Asociado de Mar "Pescados y Mariscos A.", para la instalación, explotación y funcionamiento de unos parques de cultivo de almeja fina, con ocupación de 18.000 metros cuadrados, todos ellos en terrenos de dominio público de la zona marítimo-terrestre, situados en la margen norte del Canal de Ano de la Bahía de Santoña, Distrito Marítimo de Santoña.

Contra la referida Orden, previo recurso de reposición desestimado por silencio administrativo, promovió recurso contencioso-administrativo, la Administración del Estado, representada y defendida por el señor Abogado del Estado. La Sala de este orden jurisdiccional del Tribunal Superior de Justicia de Cantabria, mediante S. 19-6-1990, desestimó el expresado recurso y, frente a dicha sentencia, la Administración del Estado promueve la presente apelación.

SEGUNDO. El señor Abogado del Estado impugna la S. 19-6-1990 sosteniendo que un acto administrativo es la concesión o autorización de establecimiento de cultivos marinos, regulado por la Ley 23/1984, de 25 de junio, y otro muy distinto la concesión de ocupación de dominio público con tales instalaciones, materia que se sujetaba a la anterior Ley de Costas de 26-4-1969 y que actualmente debe someterse a la vigente Ley 22/1988, de 28 de julio. Funda su posición en el art. 3 de la Ley de Cultivos Marinos, cuyo párrafo segundo exige que cuando el otorgamiento de las concesiones o autorizaciones que este Texto Legal establece impliquen obras fijas dentro del mar, precisarán además una concesión del Organismo competente de Puertos y Costas, conforme al art. 10.3 de la Ley 28/1969, de 26 de abril. Esta remisión debe entender- 
se referida ahora al art. $110 \mathrm{~b}$ ) de la Ley $22 / 1988$. En suma, su tesis es que la autorización para la instalación de unos parques de cultivo de almeja fina, efectuada por la Diputación Regional de Cantabria, no dispensa de obtener de la autoridad competente de la Administración del Estado la concesión para la ocupación de dominio público marítimoterrestre con obras o instalaciones no desmontables, o concesión de obras fijas dentro del mar, requeridas por los art. 64 y 110.b) de la Ley de Costas de 28-7-1988. Atendiendo al contenido de la disposición adicional quinta del citado Texto Legal, el Abogado del Estado solicitó en primera instancia que se declare nula de pleno derecho la Orden de 265-1989 o, subsidiariamente, se deje demorada su eficacia hasta tanto no se obtenga el título de concesión de ocupación de los terrenos de dominio público de la zona marítimo-terrestre, que debe otorgar la competente autoridad de la Administración del Estado.

TERCERO. La sentencia impugnada y la Diputación Regional de Cantabria parten de que es competencia exclusiva de la Diputación Regional la materia de pesca en aguas interiores, marisqueo y agricultura (art. 22, número nueve, de su Estatuto de Autonomía, aprobado por Ley Orgánica 8/1981, de 30 de diciembre), habiéndose materializado la transferencia a su favor, en lo relativo a concesiones y autorizaciones de cultivos marinos, por Real Decreto 3114/1982, de 24 de julio. Afirman que el art. 112,ap.d), de la Ley de Costas de 1988 exige el informe preceptivo y vinculante de la Administración del Estado en materia de concesiones y autorizaciones de cultivos marinos. El señalado informe ya venía requerido por los art. 10 y 11 de la Ley de Cultivos Marinos, considerando este último precepto que si el informe, una vez reclamado, no se ha emitido en el plazo de un mes, debe entenderse evacuado en sentido favorable. En el expediente que dio lugar a la Orden de 26-51989, de la Consejería de Ganadería, Agricultura y Pesca de la Diputación Regional de Cantabria, objeto de la presente impugnación, consta que se solicitó el oportuno informe de la Demarcación de Costas de Cantabria y que, al no contestarse al mismo, debe entenderse que este órgano de la Administración del Estado informó favorablemente (por silencio positivo) el proyecto y la correlativa ocupación de dominio público de la zona marítimo-terrestre, necesaria para la instalación y funcionamiento de los parques de cultivo de almeja fina en cuestión. Al existir un informe estatal vinculante, declarado constitucional como instrumento de preservar la competencia estatal en materia de zona marítimo-terrestre (fundamento jurídico 7, ap.a de la Sentencia del Tribunal Constitucional 103/1989, de 8 de junio), éste es el medio de acomodación de las dos competencias concurrentes sobre un mismo espacio físico. Dicho sistema, de acuerdo con los términos en que se pronuncia la sentencia impugnada, excluye la simultánea o paralela 
MARIA DEL ROSARIO ALONSO IBÁÑEZ

tramitación de concesiones o autorizaciones de la Administración del Estado en relación con los bienes de dominio público, sustituidas en la Ley de Cultivos Marinos por el informe preceptivo y eventualmente vinculante. En síntesis, la sentencia impugnada y la Diputación Regional de Cantabria entienden que las autorizaciones que otorga la Comunidad Autónoma para la instalación de parques de cultivo de moluscos, aunque comporten ocupación de terrenos de dominio público de la zona marítimo-terrestre, no requieren la concesión de los órganos de la Administración del Estado a que aluden los arts. 64 y 110.b) de la Ley de Costas de 1988. Conviene añadir que la Cooperativa de Trabajo Asociado de Mar "Pescados y Mariscos A." - titular de la autorización impugnada - fue debidamente emplazada en la primera instancia de este proceso sin que conste su comparecencia.

CUARTO. Planteada la cuestión en los términos expresados anteriormente, debemos indicar que la misma se encuentra en la actualidad resuelta por la Sentencia del Tribunal Constitucional 149/1991, de 4 de julio, que decidió los recursos de inconstitucionalidad promovidos contra la Ley 22/1988, de 28 julio, de Costas. El art. 132.2 de la Constitución considera bienes de dominio público estatal, entre otros, y en todo caso, la zona marítimo-terrestre, las playas y el mar territorial, aunque el Tribunal Constitucional se preocupa de recordar que, como ha manifestado en sus SS. 77/1984, 227/1988 y 109/1989, "la titularidad del dominio público no es, en sí misma, un criterio de delimitación competencial y que, en consecuencia, la naturaleza demanial no aísla a la porción del territorio así caracterizado de su entorno, ni la sustrae de las competencias que sobre este aspecto corresponde a otros entes públicos que no ostentan esa titularidad" (fundamento jurídico 1 ap.C. de la S. 149/1991). El art. 64 de la Ley 22/1988, de Costas, exige que toda ocupación de los bienes de dominio público marítimo-terrestre estatal con obras o instalaciones no desmontables se sujete a previa concesión otorgada por la Administración del Estado. El Tribunal Constitucional establece la doctrina de que la Ley de Costas "ha configurado la concesión demanial como título de ocupación del dominio público, no como medida de intervención en garantía de las leyes sectoriales (como la de Cultivos Marinos, añadimos), que recaigan sobre la actividad, la obra o incluso la misma zona a la que se refiere la concesión". Así lo justifica, a juicio del propio Tribunal Constitucional, el art. 65, según el cual el otorgamiento de la concesión demanial no exime a su titular de las concesiones y autorizaciones que sean exigibles por otras Administraciones Públicas en virtud de sus competencias específicas, llegando a la conclusión de rechazar la inconstitucionalidad del art. 64 de la Ley de Costas y, por tanto, proclamar la validez de la concesión que dicho precepto requiere (fundamento jurídico 4, ap.G., 
JURISPRUDENCIA

letra a, de la S. 149/1991). Analiza también el Tribunal Constitucional el art. 110.b) de la Ley de Costas, que atribuye a la competencia de la Administración del Estado las concesiones para ocupación del dominio público marítimo-terrestre, punto respecto al que no estima las impugnaciones hechas valer por las razones ya expuestas anteriormente, y las concesiones de obras fijas en el mar, y, en cuanto a este extremo manifiesta que «es obvio que la competencia autonómica sobre ordenación del territorio no se extiende al mar y que, excluida la competencia sobre puertos, no afectada por esta previsión, las restantes competencias sectoriales asumidas por las Comunidades Autónomas (pesca, agricultura - aunque el Alto Tribunal tal vez ha querido referirse a la acuicultura-, etc.) no dispensan a quienes realizan estas actividades de la necesidad de obtener la correspondiente concesión demanial, cuando la realización de las mismas implica la ocupación del dominio público marítimo-terrestre y, "a fortiori" la del mar territorial» (fundamento jurídico 7, ap, A, letra a, de la reiterada S. 149/1991).En razón de ello sólo se declara inconstitucional y consiguientemente nulo el art. 110 ap. b) en cuanto incluye las autorizaciones en la zona de protección (núm. 1 del fallo), siendo constitucionalmente legítimo atribuir a la Administración del Estado las concesiones relativas al demanio, con el alcance que se precisa en el fundamento jurídico 4 de la repetida sentencia. Aborda el Tribunal Constitucional la validez del art. 112.d) de la Ley de Costas, que atribuye a la Administración del Estado la competencia para emitir informe, con carácter preceptivo y vinculante, respecto a las concesiones y autorizaciones de cultivos marinos, de acuerdo con su legislación específica (art. 10 y 11 de la Ley 23/1984, de Cultivos Marinos, ya citados en el anterior fundamento de derecho de la presente sentencia).El Tribunal Constitucional declara que no es inconstitucional el art. 112 siempre que se interprete en el sentido de que el informe de la Administración Estatal sólo será vinculante cuando las objeciones propuestas se basen en el ejercicio de sus propias facultades, pero no cuando aludan a normas cuya ejecución corresponde a las Comunidades Autónomas (núm. 2. ${ }^{\circ}$ del fallo y Fundamento Jurídico 7 ap. A, letra c).De lo expuesto se deduce que el Tribunal Constitucional se pronuncia porque en aquellos casos, como el ahora enjuiciado, en que es necesario obtener de la Diputación Regional de Cantabria una autorización para la instalación de unos parques de cultivo de almeja fina, conforme a lo prevenido en la Ley 23/1984, de Cultivos Marinos, ello no dispensa al sujeto que realiza tales actividades (la Cooperativa de Trabajo Asociado de Mar «Pescados y Mariscos Argoños») de obtener del órgano competente de la Administración del Estado la concesión para la ocupación de los 18.000 metros cuadrados en terrenos de dominio público de la zona marítimo-terrestre en que se deben situar las instalaciones del parque. El art. 150 del Reglamento General para Desarrollo y Eje- 
cución de la Ley de Costas, aprobado por Real Decreto 1471/1989, de 1 diciembre, regula el procedimiento para el otorgamiento de autorizaciones o concesiones competencia de las Comunidades Autónomas y que necesiten también la concesión o autorización del entonces Ministerio de Obras Públicas y Urbanismo (hoy de Obras Públicas y Transportes) para la ocupación del dominio público marítimo-terrestre.Dicho artículo ha sido declarado válido por la Sentencia del Tribunal Constitucional 198/1991, de 14 octubre (RTC 1991, 198) (Fundamento Jurídico 4, ap. F., letra b).En conclusión, como hemos señalado la Cooperativa de Trabajo Asociado de Mar «Pescados y Mariscos Argoños» tiene obligación de obtener de la Administración del Estado la correspondiente concesión para la ocupación de 18.000 metros cuadrados en terrenos de dominio público de la zona marítimo-terrestre, sin que de ello le dispense la autorización otorgada por la Diputación Regional de Cantabria, ni el informe favorable de la Demarcación de Costas (art. 10 y 11 de la Ley de Cultivos Marinos), informe que se refiere a la procedencia de autorizar las instalaciones, pero que no implica la concesión de ocupación de bienes de dominio público marítimo-terrestre estatal.

QUINTO. La Cooperativa de Trabajo Asociado de Mar «Pescados y Mariscos Argoños" no ha obtenido la concesión de la Administración del Estado para la ocupación de terrenos de dominio público marítimo-terrestre, necesaria para la instalación de los parques de cultivo de almeja fina que le ha autorizado la Diputación Regional de Cantabria.Ello determina la aplicación de la Disposición Adicional Quinta de la Ley 22/1988, de Costas. La referida Disposición Adicional únicamente ha sido declarada inconstitucional por la Sentencia del Tribunal Constitucional 149/1991, de 4 julio, en las palabras «en todo caso», expresadas en su apartado segundo. Debe pues aplicarse ahora el referido apartado, según el cual, cuando las autorizaciones que sean exigibles por otras disposiciones legales (La Ley de Cultivos Marinos) se obtengan con anterioridad al título administrativo requerido por la Ley de Costas, la eficacia de aquellas autorizaciones «quedará demorada" hasta el otorgamiento de dicho título administrativo. Es decir, la Disposición Adicional Quinta de la Ley de Costas no sanciona con la nulidad la autorización concedida por O. 26-5-1989 de la Consejería de Ganadería, Agricultura y Pesca de la Diputación Regional de Cantabria, sin haber obtenido previamente la oportuna concesión estatal para la ocupación de terrenos de la zona marítimo-terrestre. En este sentido debe desestimarse la pretensión de nulidad de la mencionada Orden que en primera instancia formuló la representación de la Administración del Estado. Lo que impone la repetida Disposición Adicional Quinta es que la eficacia de la autorización otorgada por la Diputación Regional de Cantabria quede demorada hasta que la Cooperativa inte- 
JURISPRUDENCIA

resada obtenga el otorgamiento de la concesión de la Administración del Estado para la ocupación de los 18.000 metros cuadrados necesarios en terrenos de dominio público de la zona marítimo-terrestre, y en este sentido debemos pronunciarnos, estimando en parte el recurso de apelación promovido por el señor Abogado del Estado, en la representación que le es propia.

(Sentencia de 29 de enero de 1993.Art. 71. Ponente: M. Goded Miranda).

\section{URBANISMO}

1. Plan Parcial que afecta a ámbito del litoral calificable como zona marítimo terrestre. La falta del informe de la Administración del Estado afecta a la validez formal del proceso seguido para la elaboración del planeamiento. Informe de carácter esencial y de orden público. Competencias estatales y autonómicas en la zona marítimo-terrestre. Competencias municipales en materia de planeamiento.

\section{FUNDAMENTOS DE DERECHO}

(Sentencia apelada)

SEGUNDO.Desde el punto de vista de las atribuciones estatutarias de la C.A. de Cataluña, la Administración demandada sostiene la indudable competencia exclusiva que para ordenar el litoral le atribuye el art. 9.9 EAC, sin reserva alguna en favor del Estado, pero no por ello deja de reconocer matizadamente, y con cita de decisiones del Alto Tribunal de Garantías, la necesidad de acomodación de las potestades y facultades concurrentes en un mismo ámbito territorial por parte de ambas Administraciones. Si en principio puede contradecir abiertamente el propio contenido estatutario y la jurisprudencia del Tribunal Constitucional que los acuerdos de la Comisión Mixta Estado-Generalidad de Cataluña a que se hace referencia excluyan la potestad ordenadora de la Generalidad de Cataluña respecto de la zona marítimo-terrestre, como así expresa el punto B.1 en la medida en que ni la definición de competencias le corresponde a dicho órgano paritario ni es aceptable que la mera titularidad del dominio público marítimo sirva para «aislar una porción del territorio de su entorno y considerarlo como zona exenta de las competencias de los diversos entes públicos que las ostenten" -STC 77/1984, 3 de julio- no por ello puede faltar el instrumento idóneo para que los fines sectoriales diversos de una y otra Administración que recaen sobre una misma franja o porción del 
territorio se compatibilicen y armonicen entre sí como encuadradas en el ejercicio de una soberanía política única bajo las fórmulas de cooperación institucional que la propia sentencia constitucional proclama. Podrá entonces discutirse sobre la perfectibilidad del sistema del informe vinculante de una Administración sobre otra pero es indudable que surgió del régimen paccionado propio de la actividad de la Comisión Mixta que, al menos superficialmente, le atribuye legitimidad de origen a los efectos de compatibilizar los principios de unidad y autonomía en que se apoya la organización territorial del Estado tal y como viene definida esa necesidad por la sentencia constitucional 76/1983, de 5 de agosto, y si bien se refuta toda noción de control y vigilancia que coloque a las CC.AA. en situación de dependencia jerárquica respecto de la Administración del Estado, no es factible adecuar medios e instrumentos de concurrencia competencial que no articulen algún grado o fórmula impeditiva de que la voluntad reglada o discrecional de una Administración prescinda de la otra. La técnica del informe denegatorio vinculante propende al control previo de la legalidad de las ordenaciones previstas por el planeamiento costero y no a predeterminar el contenido concreto de la ordenación en el ámbito de la función exclusiva de la Generalidad que podría derivar de su espúrea utilización.

TERCERO. Lo que sí merece especial atención es el alcance material de la actividad de la Administración competente para ordenar el litoral que dicho precepto condiciona frente a la posición argumental de las partes procesales demandada y coadyuvante que refieren su aplicabilidad únicamente a la hipótesis del planeamiento específico del litoral según interpretación más que literal forzadamente restrictiva, debe proclamarse como fórmula interpretativa más segura y sistemáticamente defendible la que propone la parte actora de que la norma afecta a todo planeamiento general o especial con incidencia en el litoral pues siendo claro que el precepto abarca un objeto más vasto que el del atípico urbanísticamente "plan general de playa" a que se contrae el art. 19 de la Ley 28/1969, de 26 de abril, sobre Costas, no existe fundamento de lógica jurídica que otorgue razón de ser a la norma tratándose de Planes Especiales y le prive de él cuando se trata de planeamiento general, sea de nivel municipal o de sector. Aunque también aquí de modo matizado y orientativo debe hacerse mención de la expresión "todo el planeamiento territorial y urbanístico que ordene el litoral» que contiene el art. 117 de la nueva Ley de Costas para encuadrar convenientemente la lógica de la norma que se interpreta. Se entra así en la necesidad de estimar los fundamentos de fondo de la pretensión y precisar su alcance en torno a la nulidad de actuaciones del trámite de aprobación del Plan Parcial impugnado y su ineludible retroacción al momento de producción del vicio invalidante, que se sitúa en la fase de «informa- 
ción oficial» de los Planes, debiendose entender por tal la de información pública posterior a la aprobación inicial regulada por el art. 128 del Reglamento de Planeamiento Urbanístico en relación con el art. 138.2 del mismo texto reglamentario. Sin embargo, dicha ubicación, coincidente con la prevista por el art. 2.1 de la Ley 3/1984, de 9 de enero, no impide la conservación y subsistencia del propio trámite de información pública inalterable por razón del defecto de tramitación art. 52 LPA- y sí la retroacción debería llevarse al momento anterior a la aprobación provisional -art. 130 RGU-, en que la Corporación Local que la otorgó hubo de tener en cuenta el resultado de los informes emitidos e introducir en su caso las modificaciones procedentes, otro momento no obstante es el que resulta de referencia sobre la base de la aplicable legislación, la aprobación definitiva según el texto del acuerdo en su punto B)1, de aplicación al caso de autos por su mayor coherencia con el carácter de las Administraciones supramunicipales a que vincula y por permitir conservar el máximo de actuaciones previas incluida la aprobación provisional no condicionada por la norma. De otro lado, es de todo punto inatendible la pretensión subsidiaria de la coadyuvante Junta de Compensación del sector del Temple, de que los efectos de la anulación del acto aprobatorio del Plan Parcial se limiten al minoritario subsector marítimo del mismo, sujeto a ejecución por sistema de expropiación, dejando a salvo las determinaciones afectantes al mayoritario subsector terrestre, pues al tratarse de infracción procedimental y no de carácter sustantivo, aquel defecto de tramitación vicia en bloque y radicalmente el acto aprobatorio que culmina el procedimiento de elaboración del planeamiento sectorial, que queda aquejado de una indivisible invalidez por razón de su dependencia de los anteriores actos de trámite - art. 50.1 LPA - y sin que a falta de trámites anteriores pueda concebirse una parcial validez y eficacia del Plan como incluso viene a ratificar el contenido del art. 53.5 LPA.

\section{FUNDAMENTOS DE DERECHO (Tribunal Supremo)}

TERCERO. En cuanto al fondo del asunto, tal como anteriormente se dejó acotado, las alegaciones de ambas partes apelantes, sustancialmente coincidentes, en forma alguna son susceptibles de desvirtuar los correctos razonamientos de la Sala de instancia, que en su totalidad han sido aceptados, motivo por el que se impone la desestimación de las apelaciones y la confirmación de la sentencia apelada. En efecto, por una parte, el que el art. 9.9 del Estatuto de Autonomía para Cataluña, aprobado por ley Orgánica 4/1979, de 18 de diciembre, atribuya a la Generalidad de Cataluña competencia exclusiva en la materia relativa a 
«ordenación del territorio y del litoral, urbanismo y vivienda», y el que el art. 25 del mismo le confiera en sus competencias exclusivas la potestad legislativa y la reglamentaria,en uso de la cual promulgó la Ley $3 / 1984$, de 9 de enero, de medidas de adecuación del ordenamiento urbanístico de Cataluña, no empece a que en la formulación y aprobación de planes de ordenación territorial deba recabar informe de los Organismos de la Administración del Estado competentes en materia de dominio público marítimo, tal como se establece en el Real Decreto $3301 / 1981$, de 18 de diciembre, toda vez que el que las Comunidades Autónomas hayan asumido en sus Estatutos competencias, no las competencias, no quiere decir que hayan asumido todas las existentes y posibles, sino únicamente las que no sean competencias exclusivas del Estado, por lo que aun siendo cierto que las competencias asumidas por las Comunidades Autónomas en sus Estatutos son ya autonómicas y no estatales, se requiere que en los correspondientes Decretos de traspasos o transferencias de servicios y medios se concrete también cuál es la competencia que han podido asumir y asumen las Comunidades Autónomas, siendo así que en el correspondiente a Cataluña en materia de ordenación del litoral, el citado 3301/1981 se previó el informe de referencia, dadas las competencias que al Estado corresponden en materia de dominio público marítimo y los títulos competenciales contenidos en el art. 149.1.1 y 23 de la Constitución de 1978, informe hecho luego exigible con carácter general por los arts. 112.1) y 117 de la vigente Ley de Costas 22/1988, de 28 de julio, declarados ajustados a la Constitución por Sentencia 149/1991, de 4 de julio, del Tribunal Constitucional, e informe comprendido tácitamente en el art. 2.1.d) de la precitada Ley $3 / 1984$, de 9 de enero. Por otra parte, el que el informe de referencia tan sólo sea exigible en los planes de ordenación de las zonas del litoral y no en los planes que en un ámbito más amplio ordenen el litoral también, es una afirmación que sólo es sostenible en una interpretación meramente literalista del Real Decreto 3301/1981, mas no en una exégesis finalista del mismo, tendente a una protección del dominio público marítimo, que igual podría resultar afectado por un plan que lo ordenase, además de otros dominios, públicos o privados, que por un plan limitado exclusivamente a él, fuese éste el plan general de ordenación de las playas, término más restrictivo que el litoral, previsto en el art. 19 de la Ley de Costas de 26 de abril de 1969, o fuese un plan especial de los previstos en el Texto Refundido de la Ley sobre Régimen del Suelo y Ordenación Urbana de 9 de abril de 1976, lo cual ha sido corroborado por los antes citados arts. 112.a) y 117 de la Ley de Costas vigente. Además el que el informe que nos ocupa haya sido interesado con el efecto previsto en el art. 86 de la Ley de Procedimiento Administrativo, es totalmente insostenible, ya que según se desprende de la certificación sobrante al folio 39 de los autos, lo que el 16-5-1986 se remitió al 
JURISPRUDENCIA

Ingeniero Jefe del Servicio de Demarcación de Costas de Cataluña por el Alcalde de Tortosa fue un escrito referente a una solicitud de deslinde del río Ebro, al que si bien se acompañaba una copia del plano parcelario que figuraba en el expediente del Plan Parcial del Temple núm. 1, no contenía ni expresa ni implícitamente petición de informe alguno, que es lo que exige el tan citado Real Decreto 3301/1981, al expresar, "en la fase de información... se recabará informe». Y finalmente, el que en la Comisión de Urbanismo figurase un representante del Ministerio de Obras Públicas y Urbanismo, en forma alguna supone subsanación del trámite obviamente, y además, cuando se ignora si asistió a la sesión en que el Plan se aprobó y si era el competente para rendir el informe.

(Sentencia de 31 de marzo de 1993, Ar. 1608. Ponente: J. Barrio Iglesias).

2. Suspensión de efectos de licencia de obras. Art.186.3 LS (253 del vigente Texto Refundido).Cómputo del plazo de tres días en el que el Alcalde ha de dar traslado del acuerdo de suspensión a la Sala. Basta con que se remita o comunique por medio fehaciente, no siendo necesaria la entrada en el Registro del Tribunal en el mencionado plazo preclusivo.

\section{FUNDAMENTOS DE DERECHO}

PRIMERO. El Ayuntamiento de As Pontes de García Rodríguez (La Coruña) promueve recurso extraordinario de revisión, amparado en el art. 102.1.b) de la Ley de esta Jurisdicción, contra la Sentencia firme dictada, conociendo en apelación, por la Sala Tercera de este Tribunal Supremo de 23-7-1991, por la que se revocó la sentencia apelada, de la Sala de Tribunal Superior de Justicia de Galicia, y se anuló el Decreto de 23-3-1988 del Alcalde-Presidente del referido Ayuntamiento, por el que había suspendido los efectos de la licencia de obras otorgada por la Corporación municipal el 6-2-1986, para construir una casa-cuartel de la Guardia Civil en dicha localidad coruñesa, edificación que constaba de planta baja y tres alturas.Dicha suspensión de efectos de la licencia, y consiguiente paralización de las obras en curso de ejecución realizadas con dicho título, se produjo por la Alcaldía en ejercicio de la potestad que le confiere el art. 186 de la Ley del Suelo, texto refundido de 94-1976 (que constituye ahora el art. 253 del vigente texto refundido aprobado por Decreto Legislativo 1/1992, de 26 de junio), y se justificó en que dicha licencia urbanística - licencia de edificación - se hallaba afectada manifiestamente de una infracción urbanística grave, cual el exceso de alturas, al autorizar las Normas Subsidiarias Municipales, en 
dicha zona de equipamiento comunitario, una edificabilidad máxima de planta baja y dos plantas de altura. Ha de precisarse que la sentencia impugnada no examina esta cuestión de fondo, de ilegalidad parcial de la licencia, porque según aquélla señala (fundamento jurídico segundo), la discrepancia del Abogado del Estado apelante se limitó al aspecto formal del traslado en plazo del acuerdo suspensivo, sin plantear discrepancia alguna en torno a si la licencia vulneró efectivamente la normativa urbanística municipal. La demanda de revisión aduce contradicción entre la sentencia recurrida, y otras muchas anteriores también del propio Tribunal Supremo, acerca del modo de entender el cómputo del plazo de tres días en el que el Alcalde ha de dar traslado directo de su acuerdo de suspensión a la Sala de lo Contencioso-Administrativo, según prescribe el art. 186.3 de la Ley del Suelo y en forma concordante, el art. 34.4 del Reglamento de Disciplina Urbanística aprobado por Real Decreto 2187/1978, de 23 junio, preceptos aplicables en la fecha de adopción del acuerdo suspensivo a que venimos aludiendo.

SEGUNDO. La identidad sustancial, tanto subjetiva como objetiva y de fundamentación, sólo se produce en rigor entre la sentencia impugnada y la pronunciada, por la entonces Sala Cuarta del Tribunal Supremo en 19-6-1979, pues sólo esta sentencia, de entre las invocadas como "antecedentes", viene contraída al supuesto de facultades suspensivas con base en el citado art. 186 de la Ley del Suelo, siendo así que las restantes, aunque inciden también en el aspecto controvertido, atañen directa y frontalmente al ejercicio por autoridades gubernativas de suspensión de acuerdos municipales y ulterior remisión a la Sala Territorial de la Jurisdicción, sin referencia específica al problema del control de legalidad urbanística y la técnica singular que el citado art. 186 del Texto Refundido en 1976 diseña, a partir de la reforma introducida en el Ordenamiento urbanístico por la Ley 19/1975 de 2 mayo.Pero aun reducido así el ámbito de las sentencias contrapuestas, la contradicción procesal que exige el art. 102.1.b) de la Ley Jurisdiccional existe y recaba un pronunciamiento dirigido a solventar los antagónicos criterios jurisprudenciales sobre la materia. Dicha contradicción, hemos de repetir, se produce en torno a la interpretación adecuada que ha de darse a la expresión "procederá (el Alcalde) en el plazo de tres días a dar traslado directo de dicho acuerdo a la Sala de lo Contencioso-Administrativo competente...», pues mientras la sentencia impugnada entiende que en dicho plazo de tres días, siguientes al de adopción del acuerdo de suspensión, ha de tener entrada en la Secretaria del Organo jurisdiccional el oficio de la Alcaldía conteniendo el texto del acuerdo suspensivo, la sentencia antecedente considera cumplido el precepto si en dicho plazo de tres días el Alcalde efectúa la comunicación o trasla- 
do a la Sala, acreditándose ello de manera fehaciente, con independencia de cuál sea la posterior fecha de entrada de dicha comunicación en el Tribunal destinatario que ha de juzgar sobre la legalidad de la licencia en cuestión.

TERCERO. Existe concordancia en las confrontadas líneas jurisprudenciales en que el referido plazo de tres días ha de computarse como días hábiles, a partir del acuerdo de la Alcaldía, y que el mismo es, como acertadamente recuerda la sentencia objeto de revisión, «un plazo fatal e improrrogable, de imperativa vigencia, plazo de caducidad, cuya inobservancia priva de efectos a la suspensión de que se trate, excluyendo el pronunciamiento sobre la existencia de la infracción". La discrepancia se produce por cuanto la línea jurisprudencial inicial u originaria toma como perspectiva sustancial la del acto administrativo de suspensión, al que la Ley anuda efectos y consecuencias procesales, mientras que la sentencia recurrida y alguna otra sentencia en esta misma dirección, adopta como prioritaria la perspectiva del enjuiciamiento y del proceso especial del art. 118 de la Ley de la Jurisdicción, entendiendo que el traslado es un modo de iniciación de dicho proceso especial, requerido de prestación o entrada en el Registro del Tribunal u Organo judicial habilitado para ello dentro del mencionado plazo preclusivo.

CUARTO. Así las cosas, la contradicción expuesta ha de dilucidarse, entiende la Sala, en favor de la primera línea o criterio jurisprudencial, y ello por las razones siguientes: a) En primer término, porque la propia redacción literal del precepto, conduce a dicha tesis, ya que trasladar a tanto equivale como a comunicar o poner en conocimiento de alguien un dato o noticia, por lo que el traslado que se impone, como carga en sentido técnico, mira al obligado al mismo, de modo que el Alcalde cumplirá si en el plazo de referencia produce una actividad de salida o comunicación a la Sala, no siendo exigible que, equiparando traslado a prestación o entrega, se entienda cumplido aquél sólo cuando el acuerdo haya tenido entrada en el Tribunal; b) Esencialmente, porque si bien es verdad que la suspensión de efectos de la licencia es un acto de los que pudiéramos llamar "a doble vertiente», administrativa cautelar de cese de eficacia o ejecutividad de un acto - la licencia-, y de otra, la iniciación de un proceso especial para depurar la existencia o no de infracción urbanística grave y manifiesta (como el regulado por el art. 118 de la Ley de la Jurisdicción), y en tal sentido cabe citar la Sentencia de la Sala Tercera, Sección 5a, de 29-5-1992, no puede olvidarse que mediante el mismo la Alcaldía no ejercita una pretensión de anulación de la misma naturaleza que si interpusiera un recurso frente a acto de otro Ente Público, o si formulase, tras declarar la lesi- 
vidad de un acto propio, la demanda a que se refieren los arts. 56 y 57.4 de la tan repetida Ley de esta Jurisdicción. Quiere decirse que si el rigor procesal de que el escrito de iniciación de un proceso administrativo tenga entrada en el Tribunal en el plazo preclusivo señalado, es predicable de los actos que de manera formal constituyan el acto de parte dirigido a poner en marcha la revisión jurisdiccional, no así cabe extender tal rigor cuando la iniciación no se produce mediante un escrito pura e íntegramente de naturaleza procesal, puesto que el acuerdo suspensivo de la Alcaldía ni es escrito de interposición de recurso contencioso-administrativo ni equivale a demanda en un proceso de lesividad. Buena prueba de esto último es que la "demanda mixta» con que se inicia el proceso especial de lesividad ha de ir acompañada del correspondiente expediente administrativo, tal como precisa el art. 57.4 antes citado, mientras que aquí, a tenor del ap. 2 del art. 118 , una vez recibido el traslado de la suspensión, la Sala requiere de la Corporación Local el envío del expediente administrativo. Al no constituir, pues, ni verdadera impugnación ni ejercicio de pretensión anulatoria mediante escritos procesales de interposición o de demanda, no cabe hacer extensivo al acto administrativo de suspensión requisitos propios y exclusivos de tales escritos y c) Finalmente, la interpretación ha de ser favorable a hacer efectiva, con la viabilidad del proceso especial del art. 118, el cumplimiento de la disciplina urbanística y el control jurisdiccional de la legalidad de la licencia, propósito que fue uno de los ejes inspiradores de la reforma urbanística de 1975, como luce en la Exposición de Motivos de la Ley (epígrafe X de la misma). La interpretación diversa aboca a eventuales resultados de licencias que amparan obras, en curso de ejecución, afectadas de manifiestas infracciones urbanísticas graves, y que consolidan sus consecuencias si tal legalidad no es depurada en vía jurisdiccional.

QUINTO. A efectos de apurar el razonamiento, podría argüirse para justificar respaldo a la tesis más rigorista antes expuesta que cuando el art. 186.3 de la Ley del Suelo habla de "traslado directo", ha de atribuirse alguna significación a esta locución, a diferencia de la de simple traslado que emplea el art. 118.1 de la Ley Jurisdiccional («darán traslado de la suspensión", es la expresión textual de precepto), y que aquélla, la contenida en la norma urbanística, bien pudiera destacar la intención perseguida de que el escrito conteniendo el acuerdo suspensivo tenga entrada en el perentorio plazo de tres días hábiles desde su adopción por la Alcaldía, en la Secretaría del Tribunal, o —como dice la propia sentencia recurrida-, que haya obrado en poder del órgano jurisdiccional en ese fugaz plazo. Más, situados en el contexto de precepto requerido de adecuada exégesis, ha de notarse que el mismo confería potestades suspensivas sobre licencias viciadas no sólo a los 
Alcaldes (ap.1) sino también a los Gobernadores civiles, bien de oficio, bien a instancia del entonces Delegado Provincial del Ministerio de la Vivienda (ap.2), facultades estas que han quedado ya eliminadas por virtud de la autonomía municipal garantizada por la Constitución (art. 140), y por el régimen de impugnación de acuerdos de los Entes Locales diseñado en la Ley 7/1985, de 2 abril, reguladora de las Bases del Régimen Local (art. 65 a 67); pues bien, por traslado directo ha de entenderse el que se produce sin intermediación de otro Organo administrativo y sin trámite intermedio de asesoramiento o dictamen. Directo quiere decir, entendemos, el que se produce desde la Alcaldía al Organo Jurisdiccional competente, sin que medie instancia alguna de cualquier naturaleza. En consecuencia, la expresión de traslado directo, que sigue utilizando el art. 253.2 del vigente texto refundido de 26-61992, no altera en modo alguno la conclusión antes alcanzada en orden a que basta con que el acuerdo suspensivo se remita o comunique por modo fehaciente, como en el correo certificado que se utilizó en el caso, dentro del plazo de tres días hábiles siguientes al de su adopción por la autoridad municipal, teniendo por destinatario a la Sala de lo Contencioso-Administrativo competente, para tener por cumplida la "condictio iuris" impuesta a la potestad suspensiva.

SEXTO. En conclusión de lo antes razonado, es procedente la rescisión de la sentencia firme objeto de este recurso extraordinario, por cuanto se estima como criterio jurisprudencial más correcto el contenido en la sentencia "antecedente», al que se atuvo la Sentencia del Tribunal Superior de Galicia, de 8-6-1989, revocada por aquélla. En orden al subsiguiente juicio rescisorio, procede efectuarlo en esta misma sentencia, por razones de economía procesal y dado que existen suficientes elementos de juicio para formularlo con suficientes garantías. A este respecto, procede en cuanto al fondo o aspecto sustantivo, la confirmación de la referida sentencia apelada, frente a cuya apreciación de ilegalidad parcial de la licencia de obras ningún alegato opuso el Abogado del Estado apelante, y por cuanto, según se desprende de las actuaciones y no ha sido contradicho por dicha parte al oponerse al recurso de revisión, la licencia de edificación otorgada, en 6-2-1986, por la Comisión Municipal de Gobierno del Ayuntamiento de As Pontes de García Rodríguez, para construir una casa-cuartel de la Guardia Civil, infringió de manera manifiesta el art. 10.2.2.6 de las Normas Subsidiarias Municipales vigentes en tal fecha (aprobadas definitivamente por la Comisión Provincial de Urbanismo en 19-12-1985 y publicadas en el Boletín Oficial de la Provincia del 22-1-1986), al autorizar una planta tercera, además de la baja y dos de altura, únicas permitidas por dicha norma urbanística en la zona de equipamiento comunitario, constituyendo así una infracción urbanística grave, como comprendida 
en el art. 226 de la Ley del Suelo en relación con el art. 54.3 del Reglamento de Disciplina Urbanística, y de carácter patente o no necesitado en especial indagación dado que se desprende de la simple confrontación entre la referida previsión de las Normas Subsidiarias y la licencia de obras, por lo que el pronunciamiento que debía recaer en sede del art. 118 de la Ley Jurisdiccional no podía ser otro sino el de la sentencia apelada, de anulación de la referida licencia, si bien -aunque ello está implícito-limitada al exceso o infracción urbanística, contraído a la tercera planta de la edificación amparada por aquel acto administrativo; pronunciamiento de anulación parcial de la licencia que se acomoda a la alternativa prevista en el ap. 5, in fine, del art.118 de constante cita, y que es el que, en fase de juicio rescisorio, ha de sustituir al de levantamiento de la suspensión que se contiene en la sentencia que ahora revisamos.

(Sentencia de 28 de enero de 1993. Ar. 248. Recurso extraordinario de revisión. Ponente: P. García Manzano).

\section{Vigencia de la potestad de suspensión de licencias}

\section{FUNDAMENTOS DE DERECHO}

CUARTO: Antes de entrar en el examen de las dos cuestiones que constituyen el fondo del asunto, procede efectuar una breves consideraciones en relación a la vigencia de la potestad de suspensión de licencias del art. 186 de la Ley del Suelo, después de la promulgación de la Ley de Bases del Régimen Local de 2-4-85 (RCL 1985, 799, 1372 y ApNDL 7018).El apelante estima que las facultades de suspensión reconocidas en dicho artículo, incluida la del Alcalde, resultan incompatibles con el sistema de autonomía local diseñado por la Constitución (RCL 1978, 2836 yApNDL 28750). Importa advertir que esta Sala, en SS. 25-1-89, y partiendo de la doctrina establecida por el Tribunal Constitucional, ha declarado que las Comunidades Autónomas carecen de competencia para suspender los acuerdos de las Corporaciones Locales en materia de urbanismo por haberse suprimido su anterior potestad tras la promulgación de la Ley $7 / 1985$ de 2 de abril, reguladora de las Bases del Régimen Local, conforme a sus artículos 65 y 66 . Ahora bien, esta doctrina no es aplicable a los supuestos, como el ahora enjuiciado, en los que la expresada facultad de suspensión es ejercitada, no por una Comunidad Autónoma, sino por el propio Alcalde del Ayuntamiento concedente de la licencia, al amparo del $n^{\circ} 1$ del citado art. 186.Así lo han entendido las Sentencias de esta Sala de 22 de Enero y 6 de febrero de 1988 y, más recientemente, aunque referida a un supuesto de subrogación del órgano autonómico por inactividad mu- 
nicipal, la de 7-11-1991, la cual, con la particularidad citada establece que «la expresada facultad que otorga al Alcalde el citado art. 186, en su ap. 1..$^{\circ}$ para disponer la suspensión de los efectos de una licencia cuando el contenido de la misma constituya manifiestamente una infracción urbanística grave, debe estimarse vigente, sin que a ello obste lo que disponen los convocados arts. 65 y 66 de la ley 7/1985 de Bases del Régimen Local, así como su Disposición Derogatoria e) ni la doctrina jurisprudencial sentada por el Tribunal Constitucional en sus Sentencias 213/1988, de 11 de noviembre y 259/1988, de 22 de diciembre... puesto que, si bien es cierto que la jurisprudencia constitucional aludida ha dejado establecido que el apartado $2 .^{\circ}$ del referido art. 186 no puede prevalecer frente al principio de autonomía municipal que consagran los artículos 137 y 140 de la Constitución, en la medida en que su aplicación pueda suponer una indebida intromisión de un órgano estatal o autonómico en la esfera de competencias estrictamente locales - Sentencia del Tribunal Supremo de 21-2-1986, entre otrasno cabe decir lo mismo respecto del ap. $10^{\circ}$ de aquel precepto, que más bien viene a reforzar... la autonomía de la Corporación que acuerda la suspensión de una licencia en virtud de subrogación, por un órgano de la Administración Autonómica...». Doctrina jurisprudencial que, en definitiva, nos conduce a rechazar el primer motivo de oposición a la sentencia apelada.

(Sentencia 16 febrero 1993. Ar. 532. Ponente: M. De Oro-Pulido y López). 
REALA-1993, núm. 260. ALONSO IBAÑEZ, MARIA DEL ROSARIO. RESEÑA DE SENTENCIAS DEL...

REALA-1993, núm. 260. ALONSO IBAÑEZ, MARIA DEL ROSARIO. RESEÑA DE SENTENCIAS DEL... 